\title{
SHIP HYDRODYNAMICS IN CONFINED WATERWAYS
}

\author{
Zhi-Ming Yuan* \\ Department of Naval Architecture, Ocean and Marine Engineering, University of \\ Strathclyde, UK
}

\begin{abstract}
The hydrodynamic performance of a vessel is highly dependent on its manoeuvring waterways. The existence of the banks and bottom, as well as the presence of the other vessels, could have a significant influence on a ship's hydrodynamic behaviour. In confined waterways, many researchers suspect the applicability of the classical potential flow method due to its nonviscous and irrotational assumption. The main objective of the present paper is to improve and develop the boundary value problem (BVP) of a potential flow method and validate its feasibility in predicting the hydrodynamic behaviour of ships advancing in confined waterways. The methodology used in the present paper is a 3D boundary element method (BEM) based on a Rankine type Green function. The numerical simulations are performed by using the in-house developed multi-body hydrodynamic interaction programme MHydro. The waves and forces (or moments) are calculated when ships are manoeuvring in shallow and narrow channels, when ships are entering locks, or when two ships are encountering or passing each other. These calculations are compared with the benchmark test data published in MASHCON (Lataire et al., 2009; Vantorre et al., 2012), as well as the published CFD (Computational Fluid Dynamics) results. It has been found that the free-surface elevation, lateral force and roll moment can be well predicted in ship-bank and ship-bottom problems. However, the potential flow solver fails to predict the sign of the yaw moment due to the cross-flow effect. When a ship is entering a lock, the return flow effect has to be considered. By adding a proper return flow velocity to the boundary value problem, the modified potential flow solver could predict the resistance and lateral forces very well. However, it fails to predict the yaw moment due to the flow separation at the lock entrance. The potential flow method is very reliable in predicting the ship-ship problem. The resistance and lateral force, as well as the yaw moment, can be predicted well by using the potential flow method.
\end{abstract}

Keywords: Bank effect; shallow water effect; ship hydrodynamics; ship-lock interaction; ship-ship interaction; encountering operation; confined waterway.

\footnotetext{
${ }^{*}$ Corresponding author at: Dep. of Naval Architecture, Ocean \& Marine Engineering, University of Strathclyde.

Henry Dyer Building, G4 OLZ, Glasgow, UK.

Tel: + $44(0) 1415483308$. Fax: +44(0)141552 2879.

E-mail address: zhiming.yuan@strath.ac.uk
} 
Nomenclature

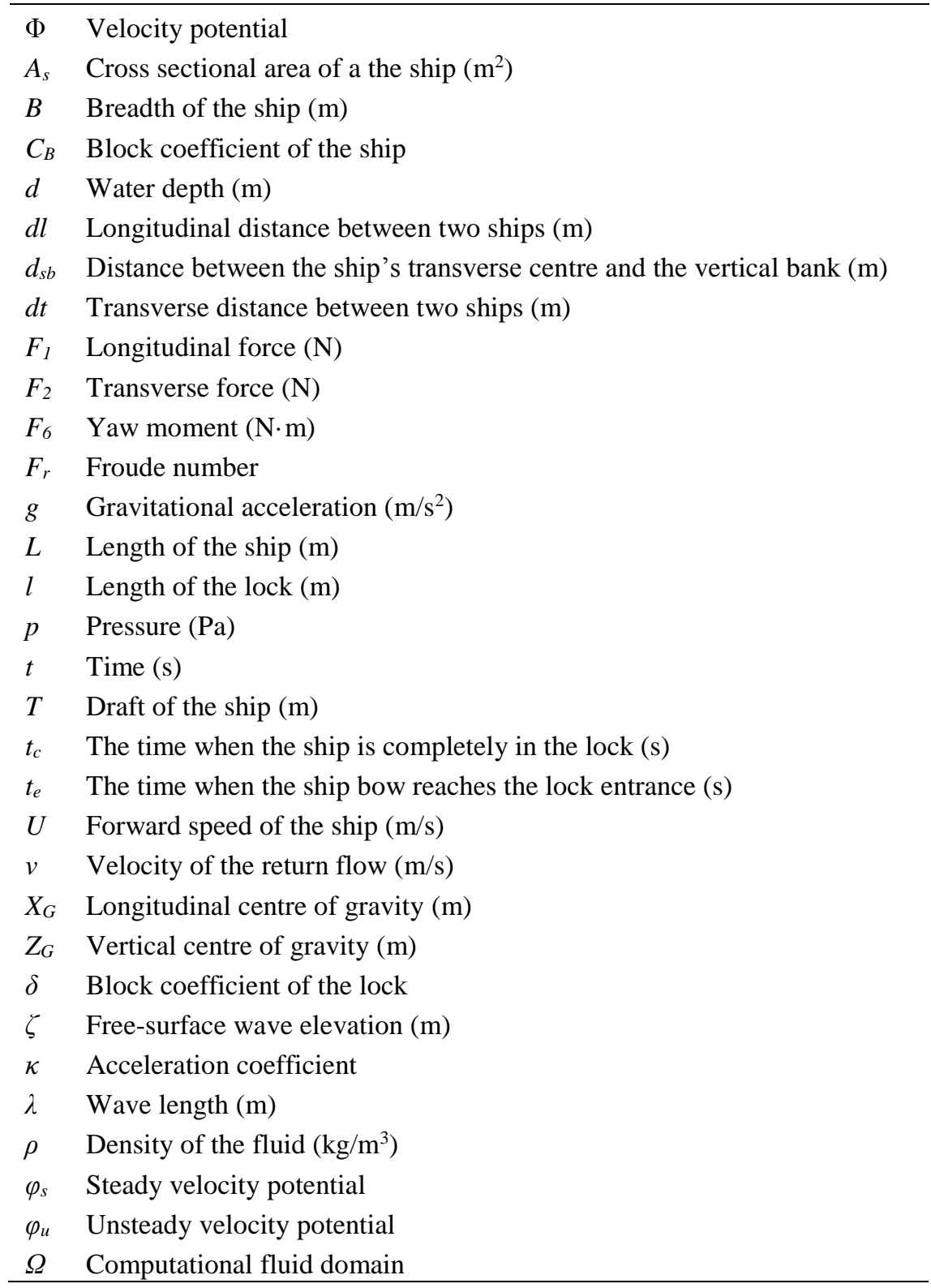

\section{INTRODUCTION}

Ships' manoeuvrability in confined waterways is continuously a topic with both academic and practical interests. As the water depth becomes small, the flow is compressed to pass under the bottom of the vessel with a higher velocity than the fluid velocity in deep water (see Figure 1(a)). According to Bernoulli's principle, the accelerated fluid velocity could result in a decrease in pressure distribution. A suction force can be predicted by integration of the pressure distribution over the ship body surface, which causes the ship to sink towards the bottom of the waterway. On the other hand, the different pressure distribution over the bow and stern of the ship could lead to a wave-making resistance and pitch moment. When the water depth becomes very small, or the forward speed increases, the wave-making resistance, sinkage and trim can reach very large values. As the resistance increases, the ship's speed loss is inevitable. And due to the large sinkage and trim (or squat), the advancing ship would have a risk of grounding. Similarly, when a ship is manoeuvring in close proximity to the bank 
(see Figure 1(b)) or the other ship (see Figure 1(c)), the flow will be compressed to pass through the narrow gaps between the ship and the bank, or between the two ships. The asymmetric flow on the port and starboard side of the ship will cause a lateral force, or a yaw moment, which may cause the ship to deviate from its original course and therefore cause collisions. For these reasons, the ships manoeuvring in confined waterways has attracted extensive interest from researchers.
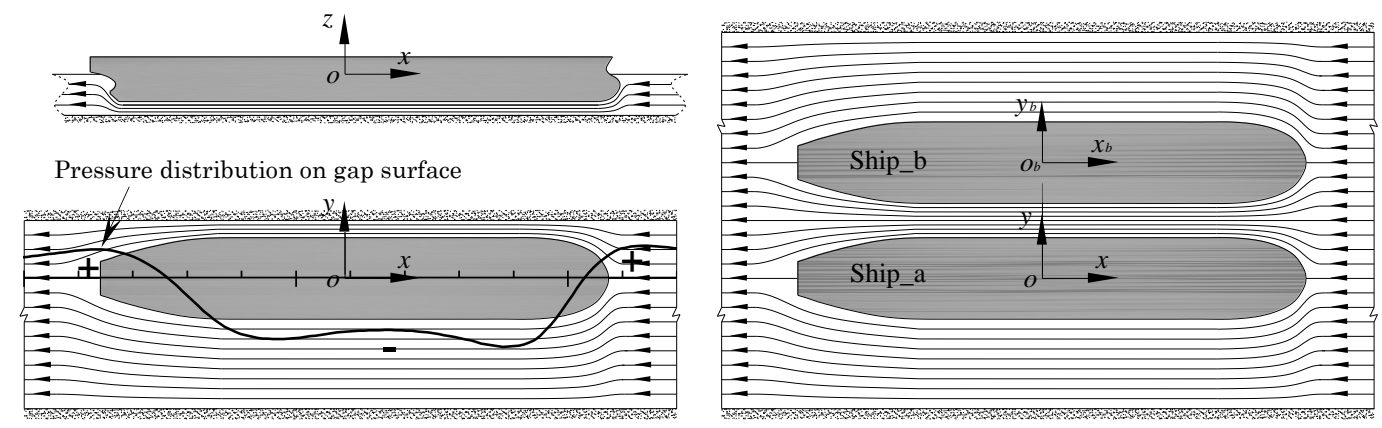

Figure 1. Sketch of flow passing the gap between (a) ship bottom and waterway bed, (b) ship and waterway banks, and (c) two ships.

In order to estimate ship-bank, ship-bottom, ship-lock and ship-ship interactions, the most reliable approach is by experimental measurements. The experimental method was extremely critical in the early years when computers were not capable of conducting large-scale analysis. The David Taylor Model Basin conducted considerable model tests to understand the cross section effects on ships manoeuvring in the Panama Canal (Schoenherr, 1960). Fujino (1968) proposed empirical formulations to estimate the lateral force and yaw moment of a ship manoeuvring in restricted waterways based on model tests carried out in the Seakeeping Laboratory of Tokyo University. Similar tests were also carried out by Eda (1971), Norrbin (1975) and Dand (1981). More recently, Flanders Hydraulics Research and Ghent University have conducted a series of model tests in their Towing Tank for Manoeuvres in Shallow Water to investigate shipbank (Lataire et al., 2016; Lataire et al., 2009; Vantorre, 1995, 2003), ship-bottom (Lataire et al., 2016; Lataire et al., 2012a), ship-lock (Vantorre et al., 2012) and ship-ship interactions (Vantorre et al., 2002). By analysing the model test data, some empirical formulae were proposed to predict the hydrodynamic forces (or moments) acting on ships in confined waterways (Lataire et al., 2012a; Lataire et al., 2012b).

The numerical method is more commonly used these days as computers are capable of solving very large matrices. The early versions of numerical programs on ship hydrodynamics in restricted waterways are mainly based on 2D methods, or so-called strip theory. Tuck $(1964,1966,1967)$, Beck et al. (1975), Newman and Tuck (1974), Yeung (1978), Yeung and Tan's (1980) approaches are within the framework of the slender ship assumption. Due to its high efficiency and fairly good prediction, it is still adopted in some recent works (Gourlay, 2008; Gourlay, 2009). The limitation of this $2 \mathrm{D}$ method is very obvious. The predictions are not accurate enough due to $3 \mathrm{D}$ effects. Also, it cannot estimate the wave-making resistance due to the assumption that the $x$-component of the normal vector is small on the whole-body surface including the bow and stern areas. To improve the accuracy of prediction, the 3D potential flow method has been widely used nowadays. From the published results and validations (Xu et al., 2016; Yao and Zou, 2010; Yuan et al., 2016; Yuan et al., 2015; Zhou et al., 
2012), it has been found that the 3D potential flow solver can generally provide a satisfactory estimation. However, the publications using 3D potential flow method to investigate the confined water problem are still very limited. The complexity of the free-surface condition is one of the reason which prevents it from being widely used, especially when it refers to the unsteady flow involved in ship-lock and ship-ship interactions. In most of the works on the 3D potential flow method, the free-surface is treated as a rigid wall (Xu et al., 2016; Zhou et al., 2012). This assumption is only reasonable when the speed of the vessel is very small. In engineering practices, the speed limitation is always applied to vessels sailing in confined waterways. The limitation of the potential flow method lies in nonviscous and irrotational assumptions. This is the reason why many researchers are still not confident with the potential flow method and doubt its reliability in confined water calculations. From this point of view, the newly emerged CFD technology seems to be a perfect replacement for ship-bank, ship-bottom, ship-lock and ship-ship problems. It is true that CFD programs are capable of investigating many complex hydrodynamic problems. But it is also a fact that CFD programs rely heavily on computational power. The numerical simulations have to be performed on High Performance Computing (HPC) platforms, especially when they are run in full scale. Even though there are some successful examples of using CFD programs to predict the hydrodynamic problems involved in confined waterways (Sakamoto et al., 2007; Tezdogan et al., 2015; Zou and Larsson, 2013a; Zou and Larsson, 2013b), the large computational time is still a problem which prevents it from being widely used in engineering practice.

The parameters which determine a ship's hydrodynamic performance in confined waterways include forward speed $u$, hull form, water depth $d$, ship-bank distance $d_{s b}$, bank slope $s$, channel cross sectional area $A_{s}$ and ship-ship distance $d_{s s}$. In order to understand the effect of each parameter, a systematic parameter study is indispensable. Due to its high efficiency, the potential flow method is still the best option to perform large-scale case studies. The main objective of the present paper is to improve and sophisticate current potential flow solver and validate its feasibility in predicting the hydrodynamic performance of ships advancing in restricted waterways. Ship-bank and ship-bottom interactions are treated as a steady flow problem, while ship-lock and ship-ship interactions are treated as an unsteady problem in the time domain. Before applying the present 3D BEM program extensively, a rigorous validation should be conducted to verify its reliability. Since 2009, the International Conference on Ship Manoeuvring in Shallow and Confined Water has successfully attracted researchers to deal with the hydrodynamics involved in confined waterways. During these conferences, Ghent University in cooperation with the Flanders Hydraulics Research (FHR), published extensive benchmark model test data related to various topics, including bank effects (Antwerp, May 2009), ship-ship interaction (Trondheim, May 2011), ship behaviour in locks (Ghent, June 2013) and shipbottom interaction (Hamburg, May 2016). The benchmark data as well as the numerical results published in these conferences will be used in the present paper to validate the applicability of the improved 3D potential flow method.

\section{SHIP-BANK AND SHIP-BOTTOM INTERACTIONS}

\subsection{THE BOUNDARY VALUE PROBLEM}

A right-handed Cartesian coordinate system $\mathbf{x}=(x, y, z)$ is fixed to a ship with its positive $x$-direction pointing towards the bow, positive $z$-direction pointing 
upwards and $z=0$ on the undisturbed free-surface. The ship is translating at forward speed $U(t)$ with respect to the space-fixed coordinate system. The fluid is assumed to be incompressible and inviscid with irrotational motion. The water wave motion is described by the velocity potential $\Phi(x, y, z, t)$ and the freesurface wave elevation $\zeta(x, y, t)$.

In the body-fixed reference frame, the velocity potential $\Phi(x, y, z, t)$ can be decomposed as

$$
\Phi(x, y, z, t)=\varphi_{s}(x, y, z)+\varphi_{u}(x, y, z, t)
$$

in which $\varphi_{s}(x, y, z)$ is the time-independent part and $\varphi_{u}(x, y, z, t)$ is the unsteady part representing the flow motion induced by the external disturbance such as the presence of other vessels or changes in the waterway topography. In the present study, considering the speed in the confined waterways is always restricted, the uniform-flow approximation is applied as the basic steady flow. This assumption leads to a relatively easy free-surface condition. Thus, EQ. (1) can be written as

$$
\Phi(x, y, z, t)=-U x+\varphi_{u}(x, y, z, t)
$$

The velocity potential $\varphi_{u}(x, y, z, t)$ satisfies the Laplace equation

$$
\frac{\partial^{2} \varphi_{u}}{\partial x^{2}}+\frac{\partial^{2} \varphi_{u}}{\partial y^{2}}+\frac{\partial^{2} \varphi_{u}}{\partial z^{2}}=0
$$

The dynamic and kinetic free-surface conditions are

$$
\begin{gathered}
\frac{\partial \varphi_{u}}{\partial t}-U \frac{\partial \varphi_{u}}{\partial x}+g \zeta+\frac{1}{2} \nabla \varphi_{u} \cdot \nabla \varphi_{u}+\frac{p}{\rho}=0, \text { at } z=\zeta \\
\frac{\partial \zeta}{\partial t}-U \frac{\partial \zeta}{\partial x}+\frac{\partial \varphi_{u}}{\partial x} \frac{\partial \zeta}{\partial x}+\frac{\partial \varphi_{u}}{\partial y} \frac{\partial \zeta}{\partial y}-\frac{\partial \varphi_{u}}{\partial z}=0, \text { at } z=\zeta
\end{gathered}
$$

where $g$ is the gravitational acceleration, $\rho$ is the fluid density and $p$ is the forcing pressure on the free-surface. By applying Taylor series expanded about $z=$ 0 and only keeping the linear terms, the dynamic and kinetic free-surface conditions can be linearized as

$$
\begin{aligned}
& \frac{\partial \varphi_{u}}{\partial t}-U \frac{\partial \varphi_{u}}{\partial x}+g \zeta=0, \text { at } z=0 \\
& \frac{\partial \zeta}{\partial t}-U \frac{\partial \zeta}{\partial x}-\frac{\partial \varphi_{u}}{\partial z}=0, \text { at } z=0
\end{aligned}
$$

By performing the operation $\partial / \partial t-U \partial / \partial x$ on EQ. (6) and then substituting it into EQ. (7), the combined linearized free-surface condition is then

$$
\frac{\partial^{2} \varphi_{u}}{\partial t^{2}}-2 U \frac{\partial^{2} \varphi_{u}}{\partial x \partial t}+U^{2} \frac{\partial^{2} \varphi_{u}}{\partial x^{2}}+g \frac{\partial \varphi_{u}}{\partial z}=0
$$

In ship-bank and ship-bottom problems, it is assumed that the slope of the bank and bottom is constant and the ship is travelling with constant speed $U$. Then the boundary conditions can be treated as a steady problem and EQ. (8) is now reduced to

$$
U^{2} \frac{\partial^{2} \varphi_{u}}{\partial x^{2}}+g \frac{\partial \varphi_{u}}{\partial z}=0
$$


The body surface boundary condition follows from the requirement that there be no flow through the hull surface. This means

$$
\frac{\partial \varphi_{u}}{\partial n}=U n_{1}
$$

Where $\partial / \partial n$ is the derivative along the normal vector $\mathbf{n}=\left(n_{1}, n_{2}, n_{3}\right)$ to the hull surface. The normal vector is defined to be positive into the fluid domain. The boundary condition on the sea bottom and side walls can be expressed as

$$
\frac{\partial \varphi_{u}}{\partial n}=0
$$

A radiation condition is imposed on the control surface to ensure that waves vanish at upstream infinity

$$
\varphi_{u} \rightarrow 0, \quad \zeta \rightarrow 0 \text { as } \sqrt{x^{2}+y^{2}} \rightarrow \infty
$$

A Rankine source panel method is used to solve the boundary value problem in EQ. (3), (9), (10), (11) and (12). The details of the numerical implementation are demonstrated by Yuan et al. (2014). The same in-house developed programme MHydro is utilized in the present study as the framework to investigate ship hydrodynamics in restricted waterways. Special care should be taken to implement a suitable open boundary condition to satisfy EQ. (12). In numerical calculations, the computational domain is always truncated at a distance away from the ship hull. In general, waves will be reflected from the truncated boundaries and contaminate the flow in the computational domain. In the present study, a $2^{\text {nd }}$ order upwind difference scheme is applied on the free-surface to obtain the time and spatial derivatives

$$
\frac{\partial^{2} \varphi_{u}}{\partial x^{2}}\left(\mathbf{x}_{i}\right)=\frac{1}{\Delta x^{2}}\left(\frac{1}{4} \varphi_{u}\left(\mathbf{x}_{i+4}\right)-2 \varphi_{u}\left(\mathbf{x}_{i+3}\right)+\frac{11}{2} \varphi_{u}\left(\mathbf{x}_{i+2}\right)-6 \varphi_{u}\left(\mathbf{x}_{i+1}\right)+\frac{9}{4} \varphi_{u}\left(\mathbf{x}_{i}\right)\right)
$$

According to Bunnik (1999) and Kim et al. (2005), EQ. (12) can be satisfied consequently by applying EQ. (13). Once the unknown potential $\varphi_{u}$ is solved, the steady pressure distributed over the ship hull can be obtained from the linearized Bernoulli's equation

$$
p=\rho U \frac{\partial \varphi_{u}}{\partial x}
$$

the integral of the pressure over the hull surface, the forces (or moments) can be obtained by

$$
F_{i}=\iint_{S} p n_{i} d s, i=1,2, \ldots, 6
$$

where

$$
n_{i}= \begin{cases}\mathbf{n}, & i=1,2,3 \\ \mathbf{x} \times \mathbf{n}, & i=4,5,6\end{cases}
$$

The wave elevation on the free-surface can be obtained from the dynamic freesurface boundary condition in EQ. (6) in the form

$$
\zeta=\frac{U}{g} \frac{\partial \varphi_{u}}{\partial x}
$$




\subsection{VALIDATIONS AND DISCUSSIONS}

\section{2 (a) Ship model and test matrix}

The ship model used in the ship-bank and ship-bottom problem is a very large crude oil carrier (referred to as KVLCC2 hereafter). The main particulars of the KVLCC2, designed by MOERI, in model scale with scale factor 1/75 are shown in Table 1. The model tests of bank and bottom effects are conducted at Flanders Hydraulics Research (FHR), and the measurement data, as well as the CFD results, used in the present paper is published by Hoydonck, et al. (Hoydonck et al., 2015). The towing tank at FHR is $88 m$ (length) $\times 7 m$ (breadth) $\times 0.5 \mathrm{~m}$ (depth). The towing tank is equipped with a double bank configuration along the full length of the tank. An overview of the cross section of the towing tank with banks is shown in Figure 2.

Table 1. Main particulars of KVLCC2 (model scale)

\begin{tabular}{ll}
\hline Length $(L)(m)$ & 4.2667 \\
Breadth $(B)(m)$ & 0.773 \\
Draft Amidships $(T)(m)$ & 0.2776 \\
Longitudinal CoG $\left(X_{G}\right)(m)$ & 0.1449 \\
Vertical CoG $\left(Z_{G}\right)(m)$ & 0.2776 \\
Displacement $\left(m^{3}\right)$ & 0.741 \\
Block coefficient $\left(C_{B}\right)$ & 0.8098 \\
\hline
\end{tabular}

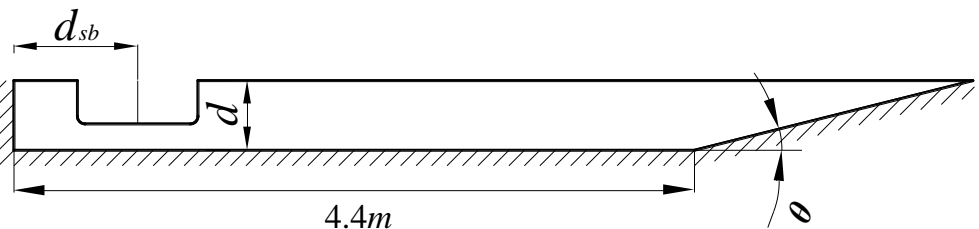

Figure 2. Cross section of the tank geometry, where $d_{s b}$ is the distance between the ship's transverse center and the vertical bank, $d$ is the water depth and $\tan (\theta)=1 / 4$.

In the present study, only the results of the ship model without propeller are present. The effects of sinkage and trim are not considered in all of the present numerical calculations. Table 2 lists the test matrix of the cases without propulsion. Case 1-Case 3 have the same water depth $(d)$, while the distance between the ship and the vertical wall $\left(d_{s b}\right)$ is different. Therefore, this set of test cases is used to represent ship-bank interaction. Case 3-Case 5 have the same $d_{s b}$, while the water depth is different. Therefore, this set of test cases is used to represent the ship-bottom interaction. In Case 1-Case 5, the Froude number $F_{r}$ $\left(F_{r}=U / \sqrt{g L}\right)$ is 0.055 .

Table 2. Test matrix of test cases without propulsion.

\begin{tabular}{lllll}
\hline Test case & $d_{s b}(m)$ & $d_{s b} / B$ & $d(m)$ & $d / T$ \\
\hline Case 1 & 0.5175 & 0.67 & 0.3744 & 1.35 \\
Case 2 & 0.5866 & 0.76 & 0.3744 & 1.35 \\
Case 3 & 0.9731 & 1.26 & 0.3744 & 1.35 \\
Case 4 & 0.9731 & 1.26 & 0.416 & 1.5 \\
Case 5 & 0.9731 & 1.26 & 0.3051 & 1.1 \\
\hline
\end{tabular}




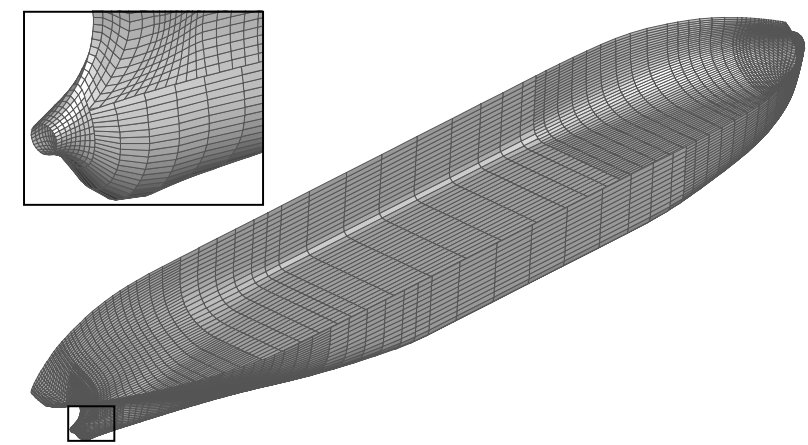

Figure 3. Panel distribution on wet body surface of KVLCC2. There are 8,080 panels distributed on the body surface.

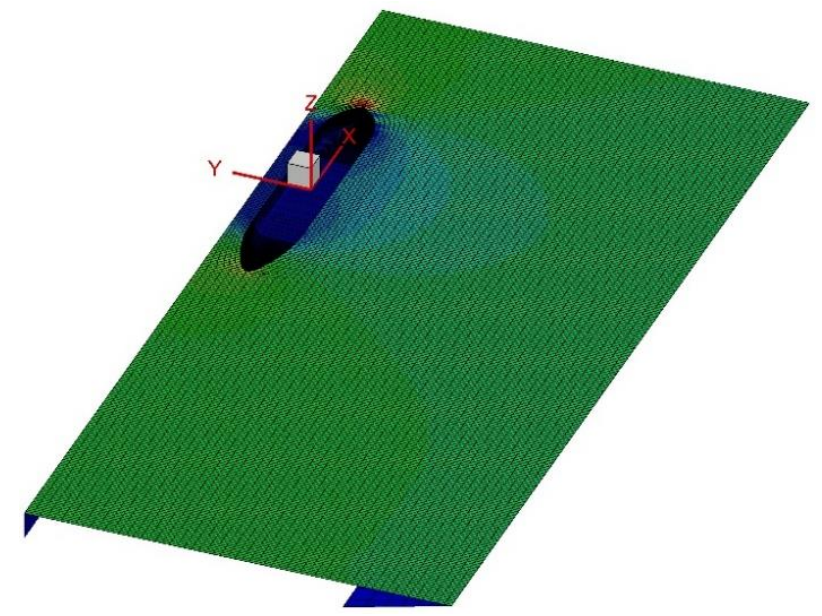

Figure 4. The coordinate system and panel distribution on the computational domain of Case 1. There are 27,060 panels distributed on the entire computational domain: 8,080 on the wetted body surface, 17,700 on the free-surface, and 1,280 on the side walls. The computational domain is truncated at $L$ upstream and $2 L$ downstream. The contour of this figure illustrates the wave elevations on the free-surface of Case 1.

Figure 4 shows the panel distribution and wave elevation of Case 1. It should be noted that in the present study, there are 100 panels distributed per ship length $(L / \Delta x=100)$. The panel size, $\Delta x$, is small enough to capture the far-field waves in most of the speed range. However, in the present study, the water depth, $d$, and the forward speed, $U$, are both very small. According to Kim's finding (Kim et al., 2005), the ratio of $\lambda / \Delta x$ should be more than 10 in order to restrain the numerical dispersion and damping. As the speed of the vessel is $0.356 \mathrm{~m} / \mathrm{s}\left(F_{r}=0.055\right)$, the corresponding wave length produced the ship is about $0.08 \mathrm{~m}$. This means $L / \Delta x$ should be at least 500 , and this is very difficult to realize in the present constant panel method. However, considering the very low forward speed in the tests, the far-field waves produced by the ship should be very small. The free-surface elevation is main dominated by near-field waves, which can only be observed in the near field of the ship. Therefore, the mesh size in the present study is still capable to capture the near-field waves, as well as the hydrodynamic forces.

2.2 (b) Validation of ship-bank problem

Figure 5 compares the wave elevations obtained from different methods. The wave gauge is located $0.02 \mathrm{~m}$ away from the vertical bank. It can be observed that the agreement between the present predictions and the experimental 
measurements are generally satisfactory. There are some fluctuations of the results obtained from the URANS solver by using a first-order time discretization, which is an unexpected phenomenon since the first-order scheme with more numerical damping is expected to be more stable. It seems that the second-order scheme can eliminate these spikes. But in all of the 3 test cases, the CFD programs overestimate the wave trough, while the present MHydro underestimates the trough. Figure 6 shows the wave profiles at the port and starboard side of the ship model. The discrepancies between these two profiles reflect the asymmetry of the flow passing the ship on either side. As shown in Figure 1 (b), the flow is compressed to pass through the ship-bank clearance with a higher velocity. According to Bernoulli's principle, the accelerated fluid velocity could result in a drop of pressure distribution. From EQ. (14) and (17) it can be found that the free-surface elevation is directly proportional to the pressure distribution on the free-surface. Therefore, the wave trough at the port side is higher than that at the starboard side, as shown in Figure 6. Because of asymmetric pressure distribution, a suction force, as well as a roll and yaw moment, can be expected, which will be discussed latter.

(a)

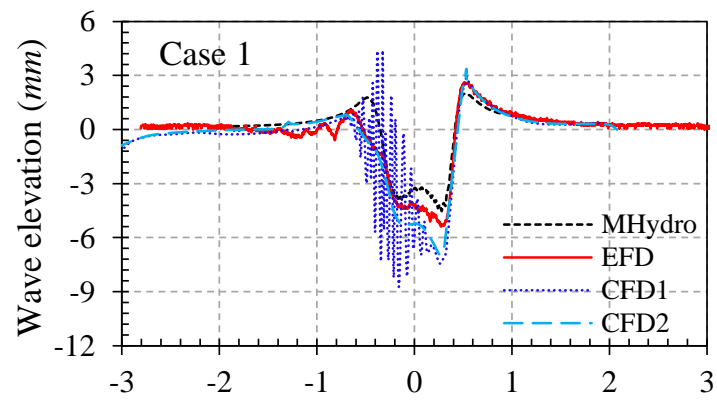

(b)

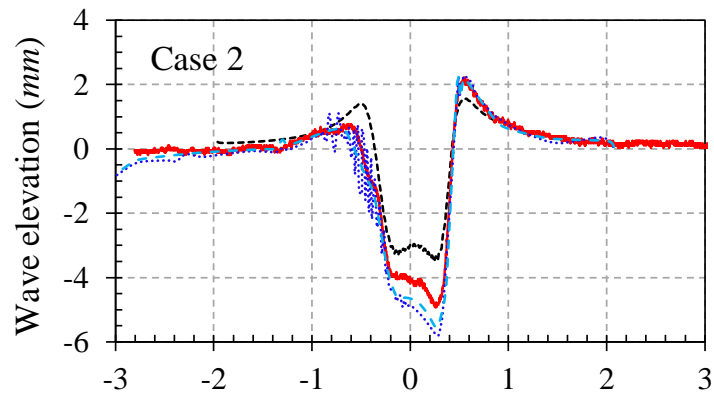

(c)

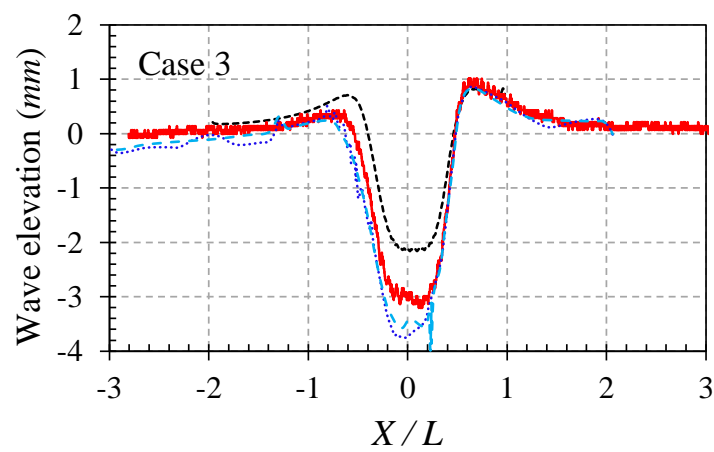

Figure 5. Results of wave elevation at different $d_{s b}$ obtained from different programs. (a) Case 1; (b) Case 2; (c) Case 3. MHydro is a potential flow solver based on 3D Rankine source panel method; EFD represents the model test results from Hoydonck et al. (2015); CFD1 represents the results obtained by an incompressible, unsteady, Reynoldsaveraged Navier-Stokes (URANS) solver by using a first-order time discretization; 
CFD2 represents the results obtained by URANS solver by using a second-order time discretization.

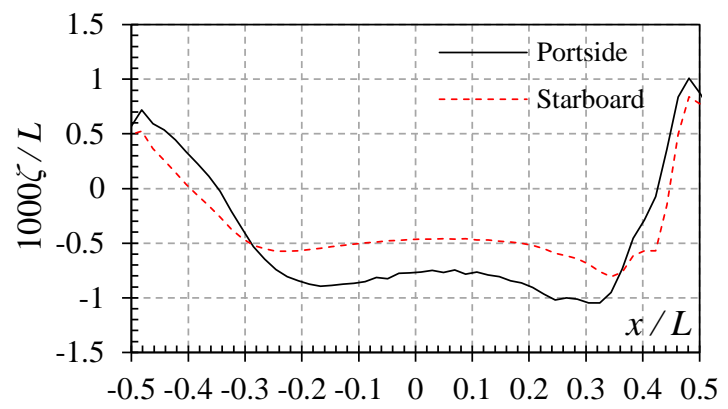

Figure 6. Wave profiles at starboard and portside of ship mode in Case 1.

Figure 7 compares the results of forces (or moments) at different ratios of $d_{s b} / B$ obtained by different programs. With regard to the lateral forces and roll moments, the present results from MHydro agrees well with the experimental results. Compared with the other CFD programs, the present potential flow program shows even better predictions. However, the sign of the yaw moment predicted by MHydro is incorrect compared to the EFD and other CFD results. This problem is also encountered by ROPES, which is a potential flow solver that neglects the free-surface effect. The reason of misestimating may be attributed to $t$ the lifting forces being ignored due to non-symmetrical flow. As shown in Figure 6, the flow from both sides approaches ship stern with different speeds. Therefore, the lifting force should be taken into account. A so-called Kutta condition must be imposed to the trailing edge in the wake region which enables the flow approaches the trailing edge from both directions, meets at the corner, and then flows away from the ship. None of the fluid flows around the corner, remaining attached to the body. The present potential flow solver MHydro is based on non-lifting assumption and the lifting force is not calculated. In shipbank and ship-lock problem, the yaw moment is very small. The lifting effect is critical to determine the sign of yaw moment. This is different from ship-ship problem, in which the yaw moment is very large and it is mainly determined by the hydrodynamic interaction. It can also be concluded from Figure 7 (a) and (b) that as the ratio of $d_{s b} / B$ becomes smaller, the lateral forces and roll moments will increase rapidly.

(a)

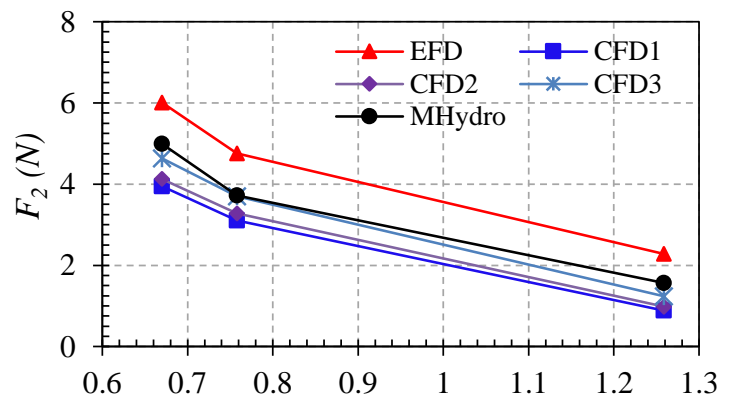


(b)

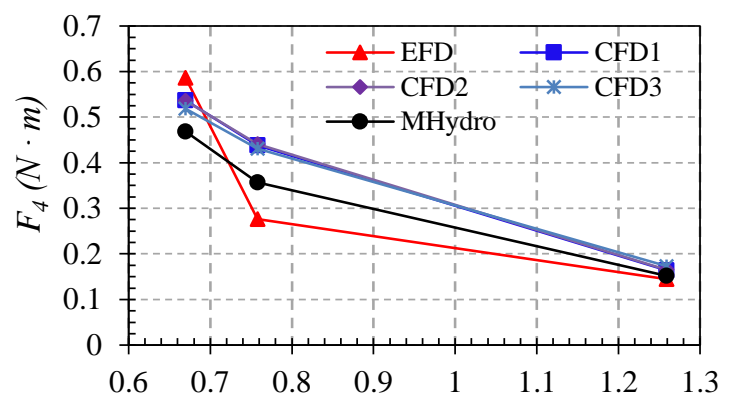

(c)

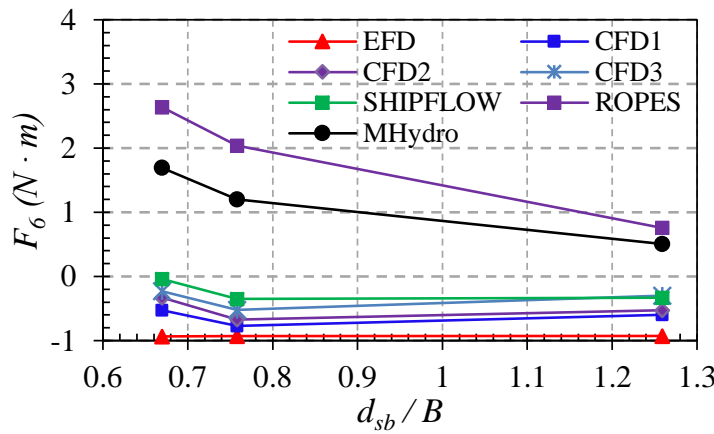

Figure 7. Comparison of forces (or moments) at different ratio of $d_{s b} / B$ from different programs. (a) Lateral forces; (b) roll moments; (c) yaw moment. The definitions of EFD, CFD1, CFD2 and MHydro are defined the same as those in Figure 5. CFD3 represents a viscous-flow CFD code ReFRESCO which solves multiphase (unsteady) incompressible flows with the RANS equations, complemented with turbulence closure models, cavitation models and volume-fraction transport equations for different phases (Vaz et al., 2009); SHIPFLOW is a steady state CFD software which contains a RANS solver XCHAP based on the finite volume method with variables collocated at cell centers (Zou and Larsson, 2013b); ROPES is a 3D potential flow program by using rigid wall condition on free-surface (Pinkster and Pinkster, 2014). All the results apart from MHydro are provided by Hoydonck et al. (2015).

\section{2 (c) Validation of ship-bottom interaction}

Case 3 - Case 5 illustrates the ship-bottom interaction. The comparison of wave elevations in Figure 8 show similar information as that shown in ship-bank interaction problem. Generally, the potential flow method is reliable of predicting the wave elevations when a ship is travelling in shallow water.

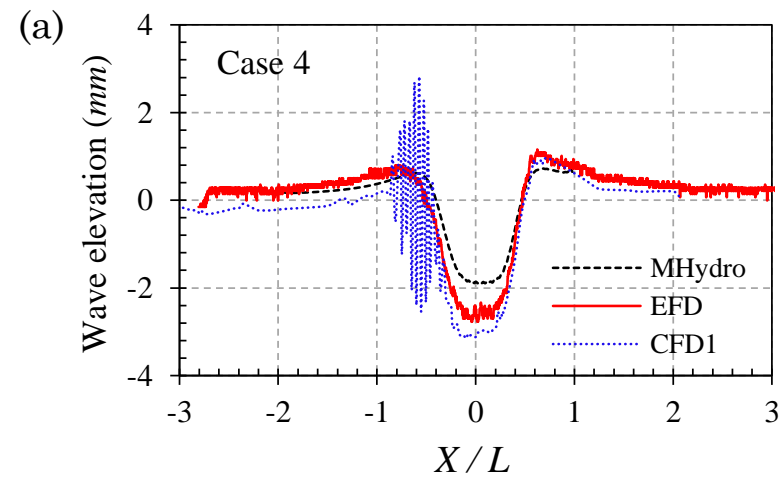


(b)

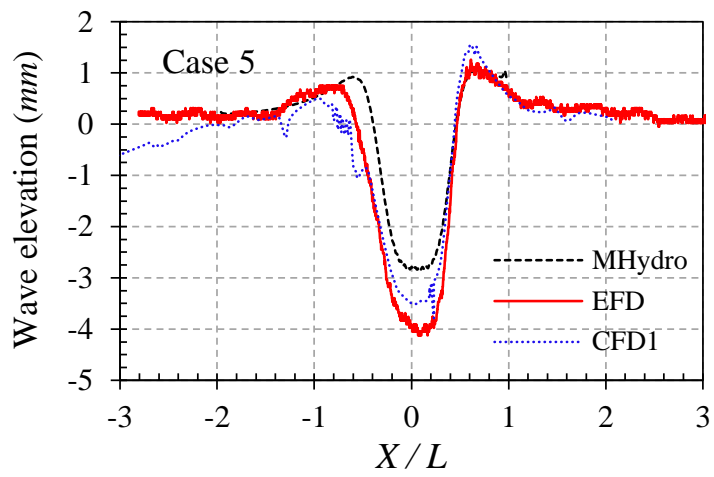

Figure 8. Results of wave elevation at different $d$ obtained by using different programs. (a) Case 4; (b) Case 5.

The comparisons of the forces and moments in Figure 9 also show similar information as that shown in ship-bank interaction problem. With regard to the lateral forces and roll moments, the present results from MHydro agree with the experimental results well. Compared with the other CFD programs, the present potential flow program shows even better predictions to some degree. However, the sign of the yaw moment predicted by MHydro and ROPES is misestimated, compared to the EFD and other CFD results. As explained above, this is due to the lifting force which is neglected in the present study.

(a)

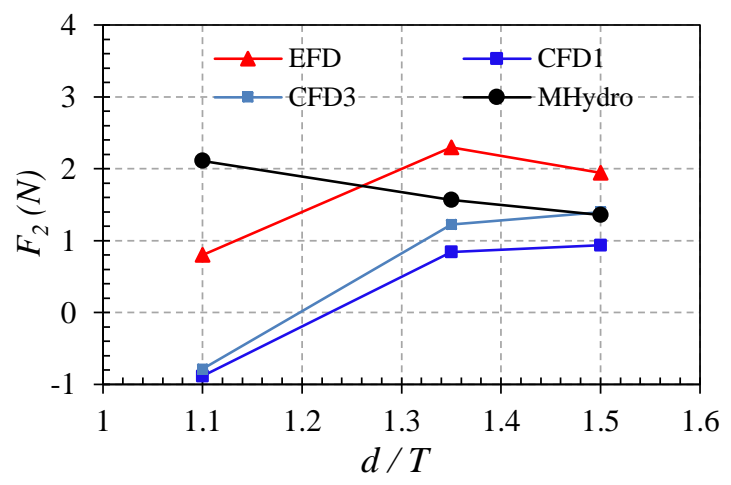

(b)

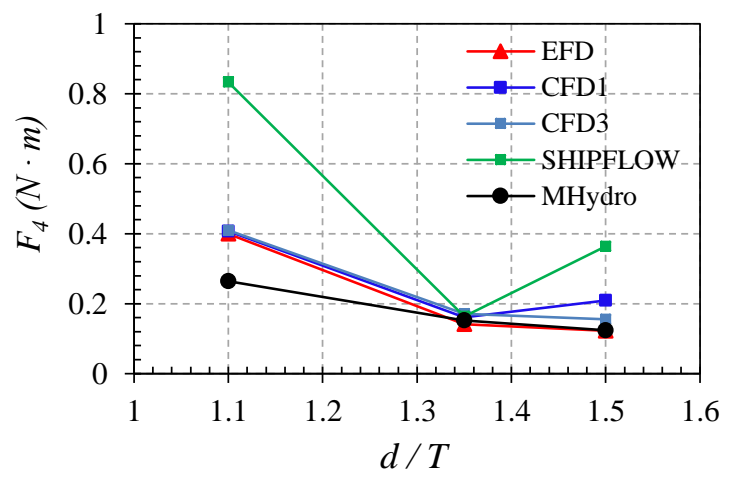


(c)

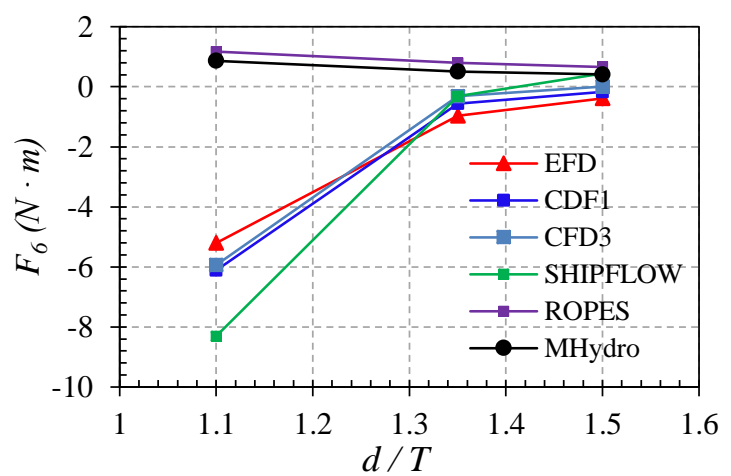

Figure 9. Comparison of forces (or moments) at different distance $d$ obtained by using different programs.

\section{SHIP-LOCK INTERACTION}

\subsection{THE BOUNDARY VALUE PROBLEM}

Ship-lock interactions are very difficult to predict. The hydrodynamics of ships entering (or leaving) a lock is always accompanied with shallow water and bank effects. When a ship enters or leaves a lock with a closed end, a so-called piston effect will be provoked due to the translation waves trapped in the narrow lock between the ship and the lock door. Meanwhile, as the water is accumulating or evacuating in a lock with closed end, a return flow will be generated. The nature of the complex hydrodynamics involved in ship-lock interactions have not been fully understood so far and it is very challenging to develop a mathematical model to predict ship hydrodynamics in a lock. Most of the available studies on the ship-lock problem are based on physical model tests (Vantorre et al., 2016; Vantorre et al., 2012). Benefiting from CFD development, some numerical studies based on CFD modelling are considered state-of-the-art (Toxopeus and Bhawsinka, 2016; Wang and Zou, 2014). The flow separation at lock entrance and its induced eddies were successfully captured. However, the free-surface deformation was neglected and the complex flow phenomenon between the ship hull and the lock door was not simulated. As a result, the forces were not predicted well when the ship approaches the door of the lock.

The only published results based on a potential flow solver (Toxopeus and Bhawsinka, 2016) are shown in Figure 10. The potential flow method only captures the initial interaction effects before the bow reaches lock entrance $(X=$ $20.5 \mathrm{~m}$ ) and completely fails to predict the full physics of the flow when the ship is partly or fully in the lock. The authors attribute the discrepancies to the viscosity, which dominates the interaction effects inside the lock. However, it cannot explain the discrepancies in lateral forces which are not dominated by viscosity, as shown in Figure 10 (b). Therefore, the discrepancies between the measured and calculated forces may be mostly due to the boundary value problem. 

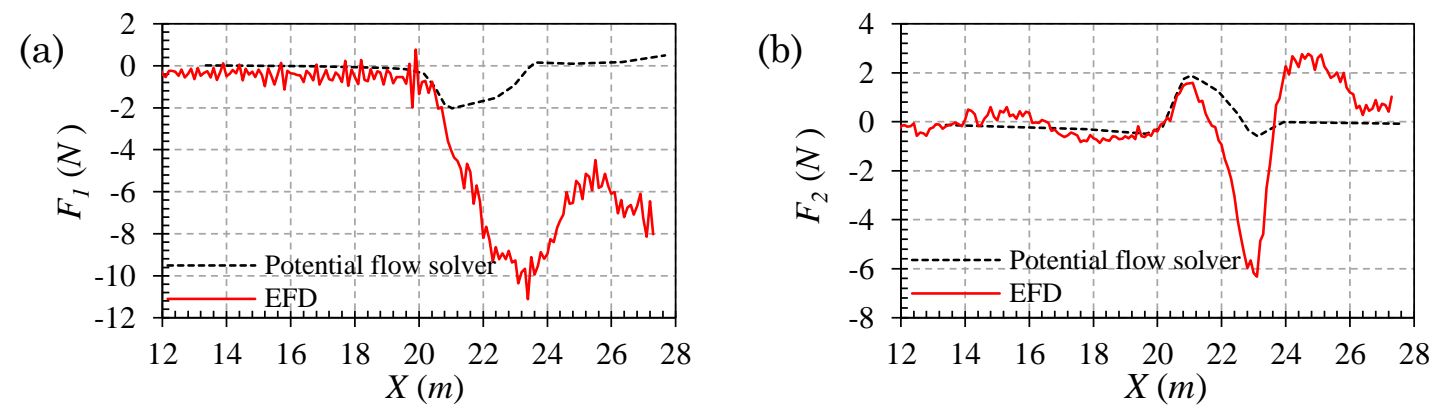

Figure 10. Resistance of a ship entering a lock. The potential flow results are provided by Toxopeus and Bhawsinka (2016) by using their in-house potential flow solver ROPES. EFD results are provided by Vantorre et al. (2012).

In ROPES, the free-surface is treated as a rigid wall and a steady boundary condition is imposed on the free-surface as $\partial \varphi / \partial n=0$. But for ships entering a lock, the boundaries at each time step are different in the body-fixed reference frame. Theoretically, the boundary value problem should be solved at each time step by applying nonlinear dynamic and kinetic free-surface boundary conditions in EQ. (4) and (5). Only in this way the complex translation waves trapped in the narrow gap can be captured. In the present study, no attempt will be made to model the flow phenomenon in the lock and its associated piston effect. Our main objective is to propose an effective methodology based on simplified empirical methods. Therefore, the time dependent term in EQ. (8) is neglected and the steady free-surface condition in EQ. (9) is still used in the ship-lock problem. The main changes are made on the body surface condition in EQ. (10).

When a ship enters a lock with a constant forward speed $U$, the water volume in the lock increases by

$$
\Delta V=U A_{s}(t) \cdot \Delta t
$$

where $A_{s}$ is the cross sectional area of the ship at moment $t$. This increased water volume will result in a return flow, which takes the same amount of water leakage through the narrow clearance. As the distance between the ship bow and the lock door decreases, the return flow velocity $v(\mathbf{x}, t)$ increases. Assuming the return flow in front of the vessel is uniform, the effect of return flow can be accounted into the body surface boundary condition in the form of an additional speed $v(t)$. Then the modified body surface condition can be rewritten as

$$
\frac{\partial \varphi_{u}}{\partial n}=(U+v(t)) n_{1}
$$

The simplified $v(t)$ can be defined as

$$
v(t)=\left\{\begin{array}{c}
0, \text { at } t \leq t_{e} \\
\kappa \frac{\delta}{l} \cdot\left(t-t_{e}\right), \text { at } t_{e}<t \leq t_{c}
\end{array}\right.
$$

where $\delta$ is block coefficient of the lock, which is defined as the ratio of the wetted cross sectional area of ship to the wetted cross sectional area of the lock. $l$ is the length of the lock. $t_{e}$ is the moment when the ship bow reaches the lock entrance and $t_{c}$ is the moment when the ship is completely in the lock. The effect of the term $\kappa \delta / l$ in EQ. (20) is equivalent to an acceleration and $\kappa$ is therefore referred to as the acceleration coefficient. At $t>t_{c}$, the total amount of water volume in the lock stays constant. The return flow mainly comes from the volume change 
in the space between the bow and the door. As the distance between bow and door decreases, the rate of volume change increases. The return flow velocity can still be determined by an acceleration coefficient. However, this acceleration coefficient will be smaller than $\kappa$. The change of the acceleration coefficient should be smooth. An empirical iteration method is introduced to estimate the return flow velocity after the ship has finished advancing in the lock, which is written as

$$
v\left(t_{n}\right)=v\left(t_{n-1}\right)+\kappa \frac{\delta}{l} \cdot \frac{U \Delta t}{\left[v\left(t_{n-1}\right)-v\left(t_{c}\right)\right]+U}, \text { at } t>t_{c}
$$

The initial condition for (21) is $v\left(t_{1}\right)=v\left(t_{c}\right)$, where $v\left(t_{c}\right)$ is calculated by EQ. (20).

By solving the boundary value problem in EQ. (3), (9), (19), (11) and (12) at each time step, the velocity potential $\varphi_{u}$ can be obtained. A $2^{\text {nd }}$ order upwind difference scheme is applied to obtain the time derivatives

$$
\frac{\partial \varphi_{u}}{\partial t}\left(t_{n}\right)=\frac{1}{\Delta t}\left(\frac{3}{2} \varphi_{u}\left(t_{n}\right)-2 \varphi_{u}\left(t_{n-1}\right)+\frac{1}{2} \varphi_{u}\left(t_{n-2}\right)\right)
$$

The unsteady pressure distributed over the ship hull can then be determined by

$$
p=-\rho\left[\frac{\partial \varphi_{u}}{\partial t}-(U+v) \frac{\partial \varphi_{u}}{\partial x}\right]
$$

The forces (or moments) can be calculated by EQ. (15). The wave elevation on the free-surface can be obtained from the dynamic free-surface boundary condition in EQ. (6) in the form

$$
\zeta(t)=-\frac{1}{g}\left[\frac{\partial \varphi_{u}}{\partial t}-(U+v) \frac{\partial \varphi_{u}}{\partial x}\right]
$$

\subsection{VALIDATIONS AND DISCUSSIONS}

3.2 (a) Ship model and test matrix

Captive model tests were carried out by Vantorre et al. (2012) in FHR. The ship model used in the ship-lock problem is a bulk carrier, with main particulars listed in Table 3 in model scale with a scale factor of 1/75. The lock configuration is shown in Figure 11 with a space-fixed coordinate system $O-X Y$. To minimize the computational domain, the long transition channel used for model test is truncated and only the part where $X>0$ is retained for the numerical calculations. The initial position $(t=0)$ in the numerical simulation starts at $X=0$. All the forces and moments are calculated in the body-fixed frame, as shown in Figure 11. Test $\mathrm{G}$ is selected as the validation case, where water depth to draft ratio $d / T=1.2$, speed $U=0.15 \mathrm{~m} / \mathrm{s}$, and the model is towed on the centerline of the lock $(Y=0)$.

Table 3. Main particulars of bulk carrier

\begin{tabular}{ll}
\hline Length $(L)(m)$ & 3.533 \\
Breadth $(B)(m)$ & 0.573 \\
Draft Amidships $(T)(m)$ & 0.231 \\
Block coefficient $\left(C_{B}\right)$ & 0.854 \\
\hline
\end{tabular}




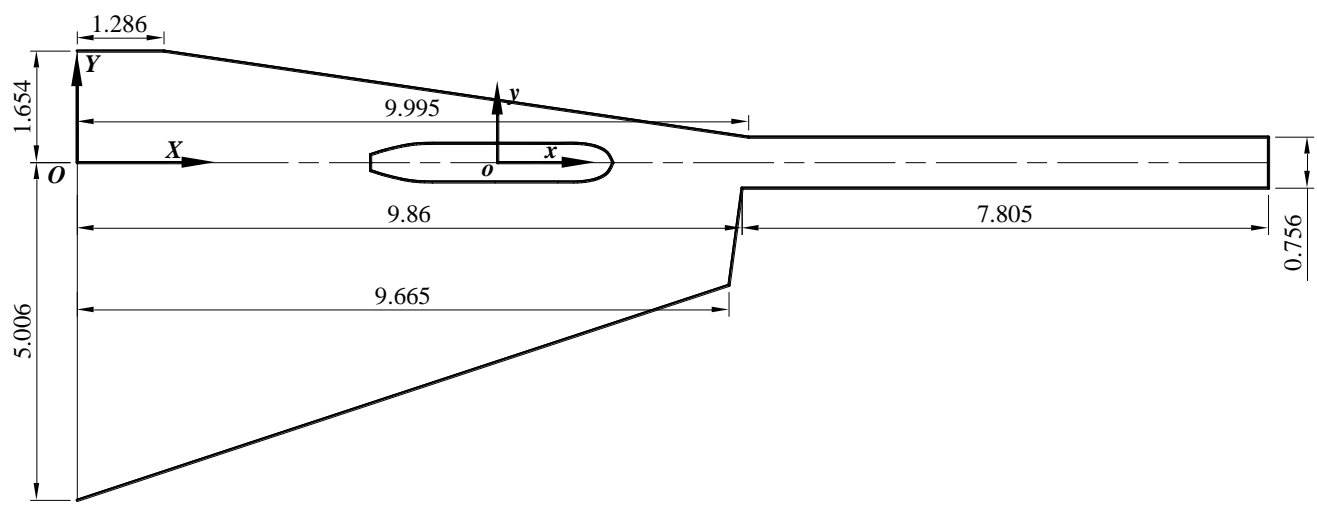

Figure 11. Configuration of the lock for captive model tests.

3.2 (b) Validations and discussions on ship-lock problem

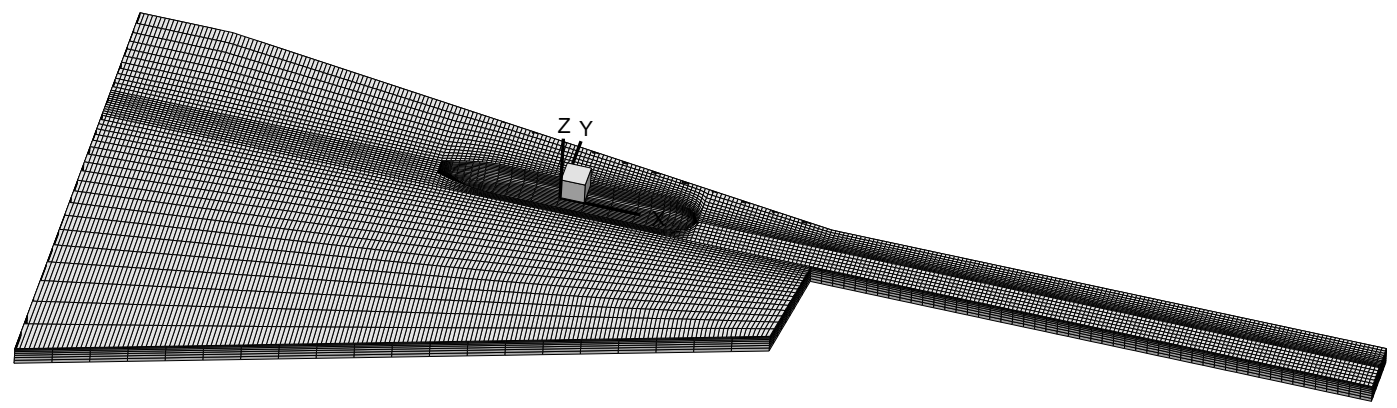

Figure 12. Panel distribution on the computational domain of Test G. There are 11,346 panels distributed on the entire computational domain: 960 on the wetted body surface, 9,874 on the free-surface, and 1,472 on the side walls.

The computational domain and mesh distribution of the present study is shown in Figure 12. A dynamic meshing technique is used, which enables an automatic update of the computational domain and mesh distribution at each time step when the ship is approaching the lock. The mesh is uniform longitudinally. Non-uniform mesh is applied only in the transverse direction due to the changes of banks and the lock walls. The results of the forces in $x-, y$-, and the moment in $x-o-y$ directions are presented in Figure 13. It should be noted that all the positive directions are consistent with the body-fixed frame shown in Figure 11. The time step $\Delta t$ in the numerical calculations is $0.39 s$.

(a)

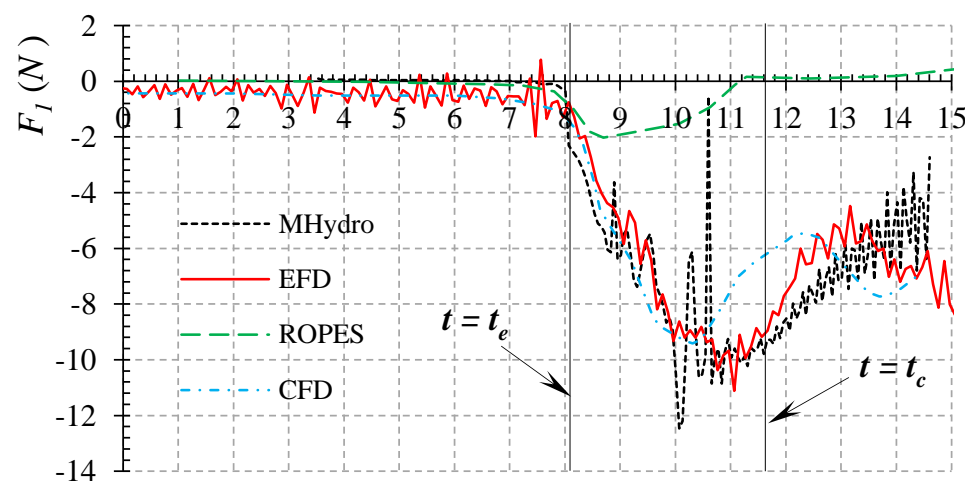


(b)

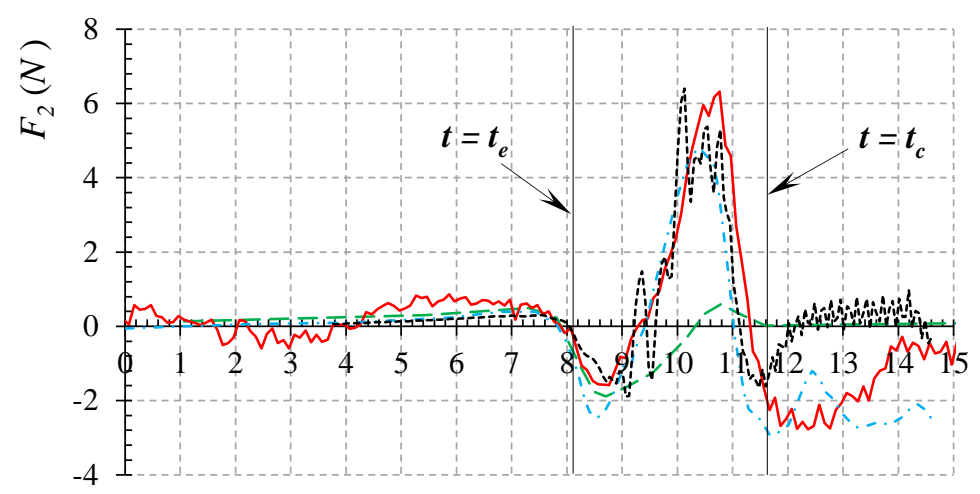

(c)

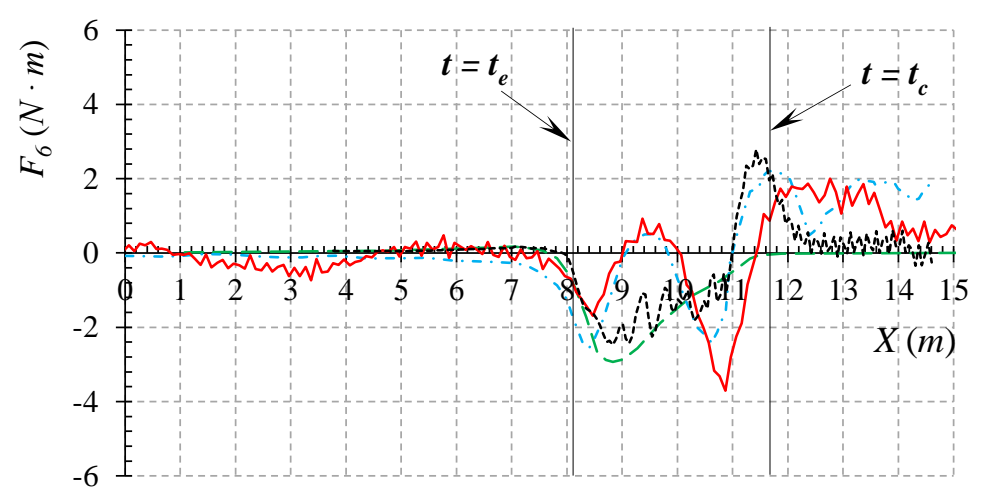

Figure 13. Validation of forces (or moments). (a) Resistance; (b) lateral force; (c) yaw moment. EFD results are provided by Vantorre et al. (2012). CFD results are published by Toxopeus and Bhawsinka (2016) by using viscous-flow code ReFRESCO. Free-surface effect is neglected in ReFRESCO. In the present MHydro program, the acceleration coefficient $\kappa=0.2$.

Figure 13 (a) shows the resistance. Before the ship enters the lock $\left(t<t_{e}\right)$, the resistance predicted by both ROPES and MHydro is very small $\left(F_{1} \approx 0\right)$. This is different from the CFD and EFD results. The discrepancies are due to the viscous contribution. The negative values at $t<t_{e}$ obtained by CFD and EFD represent the drag force contributed by viscous effects. In the present case study, the ship's speed is very low $\left(F_{r}=0.026\right)$. According to Schultz (2007), at low to moderate speeds $\left(F_{r}<0.25\right)$, the frictional resistance is the largest component of the total drag. However, when the ship starts entering the lock, the contribution of different resistance components changes. The frictional resistance is no longer the largest component. The increased return flow velocity would cause an increase in the frictional resistance leading to higher total resistance. But this increase is not significant. As shown in Figure 13 (a), the resistance increases dramatically, which is mainly caused by pressure integration due to the wave-making contribution. According to EQ. (23), the velocity potential gradient $\left(\partial \varphi_{u} / \partial t\right)$ plays a dominant role since the return flow speed and computational domain are changing at each time speed. Therefore, if a proper acceleration coefficient $\kappa$ is specified in EQ. (20) to estimate the return flow velocity, the predictions by the present potential flow solver is still satisfactory (even better than CFD solutions). When the ship is completely in the lock $\left(t>t_{c}\right)$, the total water volume will not increase, and the return flow is not as pronounced as that at $t$ $<t_{c}$. As a result, the total resistance decreases. However, as the distance between the ship bow and the lock door becomes small, the water will accumulate in the gap and a complex wave phenomenon will occur. In the CFD modelling, 
the free-surface effect is neglected (Toxopeus and Bhawsinka, 2016) and its predictions at $t>t_{c}$ are not reliable. The present potential flow solver MHydro only keeps the steady terms in the free-surface condition in EQ. (8). As the clearance between the ship bow and the lock door decreases, MHydro underestimates the resistance. As the ship gets closer to the door, the generated unsteady waves will be reflected by the door and thereafter interact with the ship, leading to an increase of resistance. Both CFD and MHydro fail to predict this piston effect by neglecting unsteady free-surface effect. A similar conclusion can also be drawn on the lateral force $F_{2}$. As shown in Figure 13 (b), the modified potential flow solver can predict the lateral force very well at $t<t_{c}$. After the ship is completely in the lock, the flow becomes symmetrical very quickly if the unsteady terms are neglected on the free-surface. As a result, the lateral forces calculated by the present potential flow solver reduce to zero shortly after the ship completely enters the lock. The results in Figure 13 (c) indicate that the present potential flow method fails to predict the yaw moment when a ship is entering a lock. This is mainly due to the flow separation which occurs at the sharp corner of the lock entrance, as well as at the ship stern. The results by Toxopeus and Bhawsinka (2016) show the importance of eddies generated at sharp corners due to flow separation, as shown in Figure 14. This violates the irrotational assumption adopted in the potential flow method. The sign of yaw moment is determined by the asymmetry of the lock configuration, while the amplitude is determined by the entering speed and blockage coefficient. As the yaw moment is critical for a ship's maneuvering in the lock area, a symmetrical lock design could help to avoid the yaw moment, as well as the lateral force.

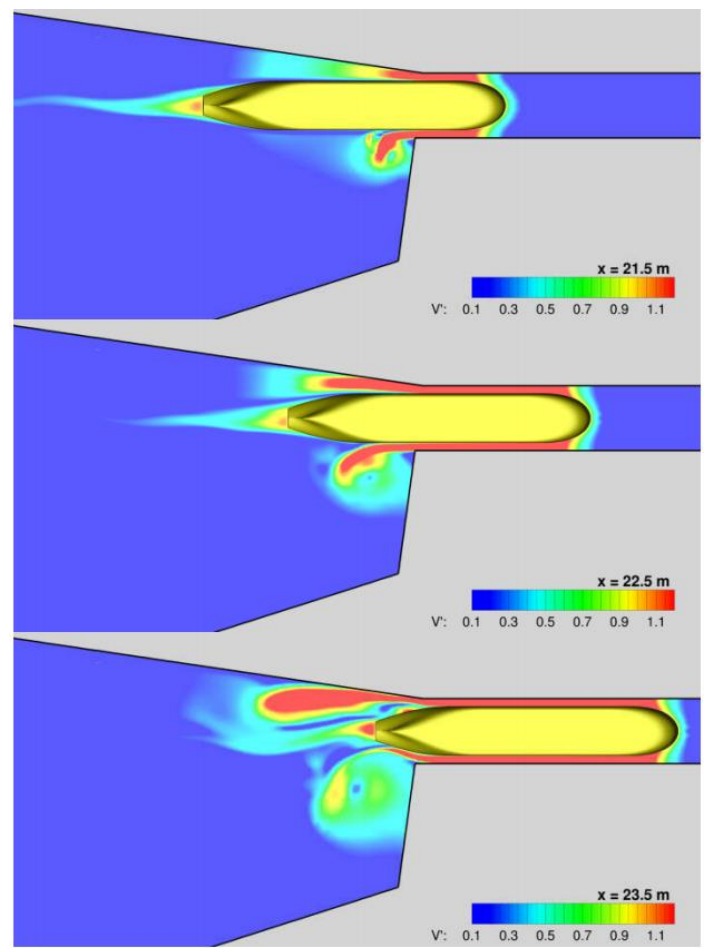

Figure 14. Visualization of the total velocity field on the free-surface by Toxopeus and Bhawsinka (2016). The $x$-coordinates presented in the figure can be transformed into the present space-fixed frame (as shown in Figure 11) by subtracting $12.335 \mathrm{~m}$.

As discussed above, the accuracy of the present calculation is highly dependent on the estimation of the return flow velocity. Figure 15 shows the return flow velocity calculated by empirical formulae in EQ. (20) and (21) with different acceleration coefficient $\kappa$. It should be noted that the return flow is assumed to be 
uniform. But in reality, the flow field is more complex. Numerical tests indicate the acceleration coefficient $\kappa$ should range from 0.1 to 0.3 . The corresponding results are shown in Figure 16. The resistance is more sensitive to the coefficient $\kappa$.

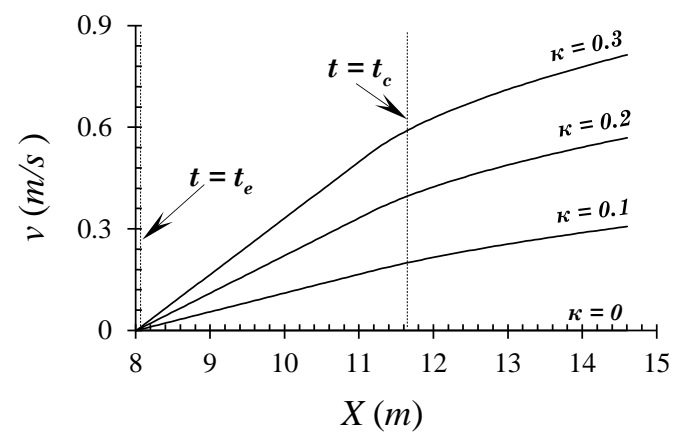

Figure 15. Return flow velocity with different acceleration coefficient $\kappa$.

(a)

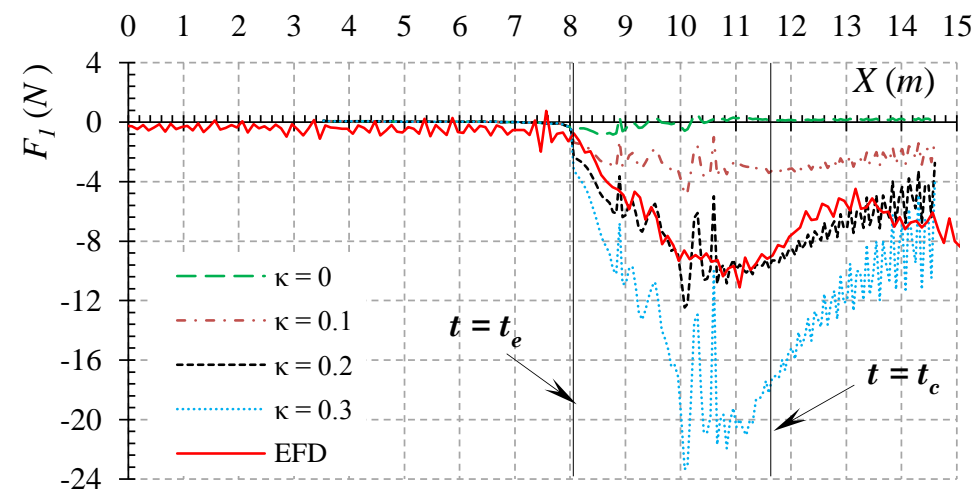

(b)

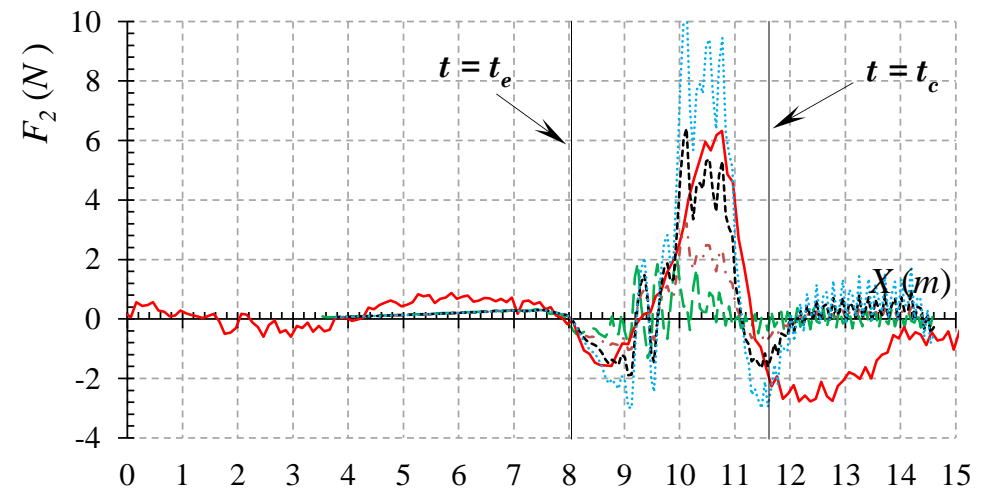

Figure 16. Comparison of forces with different acceleration coefficient $\kappa$.

\section{SHIP-SHIP INTERACTION}

\subsection{THE BOUNDARY VALUE PROBLEM}

In the previous studies on the ship-to-ship interaction problem by using the potential flow method, the rigid wall condition was applied on the free-surface as $\partial \varphi / \partial n=0$ (Xu et al., 2016; Yeung, 1978; Zhou et al., 2012). Since the speed $U$ is not included in the free-surface boundary condition, the speed of the two vessels can be arbitrary. By using multiple images, the free-surface can be treated the same as the sea bed condition. The BVP is therefore solved as a steady problem. The time dependent terms are only present in Bernoulli's Equation when calcu- 
lating the pressure distribution. This method will significantly reduce the difficulty in establishing dynamic meshes on the free-surface. However, as the encountering speed increases, this method fails to predict the wave effects.

The difficulty of taking the free-surface effect into account lies in the speed dependent terms in EQ. (8). During encountering or overtaking processes, the two ships always have different speeds. In order to account for the different speeds appearing in the free-surface boundary condition, Yuan et al. (2015) proposed an uncoupled method based on the superposition principle. In the present study, the same method will be used to investigate the ship-ship problem. Two bodyfixed coordinate systems with the same positive direction are established on Ship_a and Ship_b respectively. The velocity potential, $\varphi_{u}$, can be divided into two components

$$
\varphi_{u}=\varphi_{u}^{a}+\varphi_{u}^{b}
$$

$\varphi_{u}^{a}$ is defined as the velocity potential produced by the case when Ship_a is moving with $u_{a}$ while Ship_b is stationary. $\varphi_{u}^{b}$ is the velocity potential produced by the case when Ship_b is moving with $u_{a}$ while Ship_a is stationary. Assuming the encountering or overtaking speed is small, the time dependent terms in EQ. (8) can be neglected. Two sets of BVP are proposed to solve $\varphi_{u}^{a}$ and $\varphi_{u}^{b}$

$$
\begin{aligned}
& \frac{\partial^{2} \varphi_{u}^{a}}{\partial x^{2}}+\frac{\partial^{2} \varphi_{u}^{a}}{\partial y^{2}}+\frac{\partial^{2} \varphi_{u}^{a}}{\partial z^{2}}=0, \text { in } \Omega \\
& U_{a}{ }^{2} \frac{\partial^{2} \varphi_{u}^{a}}{\partial x^{2}}+g \frac{\partial \varphi_{u}^{a}}{\partial z}=0, \text { on } S_{f} \\
& \frac{\partial \varphi_{u}^{a}}{\partial n}=U_{a} n_{1}, \text { on } S_{a} \\
& \frac{\partial \varphi_{u}^{a}}{\partial n}=0, \text { on } S_{b} \\
& \frac{\partial^{2} \varphi_{u}^{b}}{\partial x^{2}}+\frac{\partial^{2} \varphi_{u}^{b}}{\partial y^{2}}+\frac{\partial^{2} \varphi_{u}^{b}}{\partial z^{2}}=0, \text { in } \Omega \\
& U_{b}{ }^{2} \frac{\partial^{2} \varphi_{u}^{b}}{\partial x^{2}}+g \frac{\partial \varphi_{u}^{b}}{\partial z}=0, \text { on } S_{f} \\
& \frac{\partial \varphi_{u}^{b}}{\partial n}=U_{b} n_{1}, \text { on } S_{b} \\
& \frac{\partial \varphi_{u}^{b}}{\partial n}=0, \text { on } S_{a}
\end{aligned}
$$

where $\Omega$ represents the computational fluid domain, $S_{f}$ is the free-surface, $S_{a}$ and $S_{b}$ are the wetted body surface of Ship_a and Ship_b. The unsteady pressure distributed over the ship hull can then be determined by

$$
\begin{aligned}
& p_{a}=-\rho\left[\frac{\partial \varphi_{u}}{\partial t}-U_{a} \frac{\partial \varphi_{u}}{\partial x}\right] \\
& p_{b}=-\rho\left[\frac{\partial \varphi_{u}}{\partial t}-U_{b} \frac{\partial \varphi_{u}}{\partial x}\right]
\end{aligned}
$$

The forces (or moments) can be calculated by EQ. (15). The wave elevation on the free-surface can be obtained from the dynamic free-surface boundary condition in EQ. (6) in the form 


$$
\begin{aligned}
& \zeta_{a}=-\frac{1}{g}\left[\frac{\partial \varphi_{u}^{a}}{\partial t}-U_{a} \frac{\partial \varphi_{u}^{a}}{\partial x}\right] \\
& \zeta_{b}=-\frac{1}{g}\left[\frac{\partial \varphi_{u}^{b}}{\partial t}-U_{b} \frac{\partial \varphi_{u}^{b}}{\partial x}\right]
\end{aligned}
$$

The total wave elevation can be written as

$$
\zeta=\zeta_{a}+\zeta_{b}
$$

\subsection{VALIDATIONS OF SHIP-SHIP INTERACTION}

\section{2 (a) Validation of wave elevations}

The model test data of wave elevation is published and provided by Lataire et al. (2009). The ship models involved include a KVLCC2 (as described above and it is referred as Ship_a) and an Aframax tanker model (Ship_b) with scale factor 1/75. The main dimensions of the Aframax model are $3.085 \mathrm{~m}$ (length) $\times 0.56 \mathrm{~m}$ (breadth) $\times 0.1 \mathrm{~m}$ (draft). The test condition (Test 1) is shown below: the water depth is $0.374 \mathrm{~m}$, the speed of the ships is $0.237 \mathrm{~m} / \mathrm{s}$, the transverse and longitudinal distance between the two ships is $0.9995 \mathrm{~m}$. In the numerical simulation, there are 14,040 panels $(8,080$ on the KVLCC2 model and 6,020 on the Aframax model) distributed on the body surface, 13,875 panels distributed on the free-surface, 760 panels distributed on the control surface. The free-surface is truncated at $1.5 L_{a}$ upstream and $3 L_{a}$ downstream, where $L_{a}$ refers to the ship length of the KVLCC2 model. It should be noted that $\partial \varphi_{u} / \partial t=0$ in EQ. (29) when the two ships are travelling with the same speed.

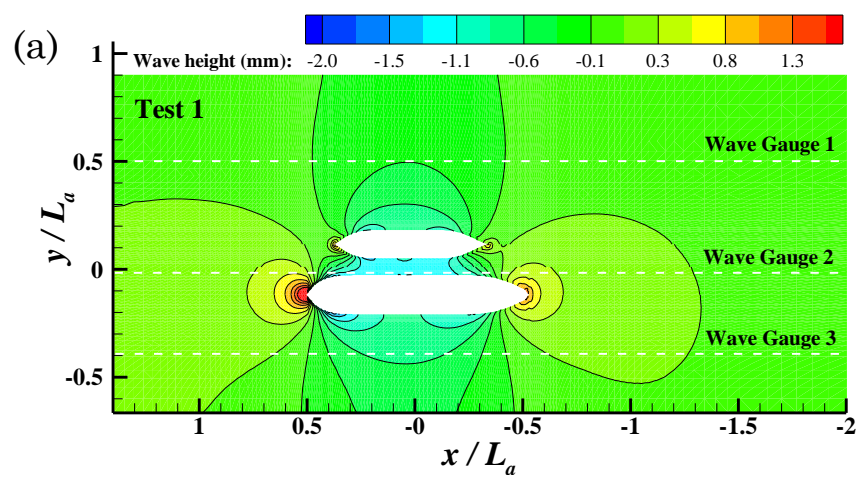

(b)

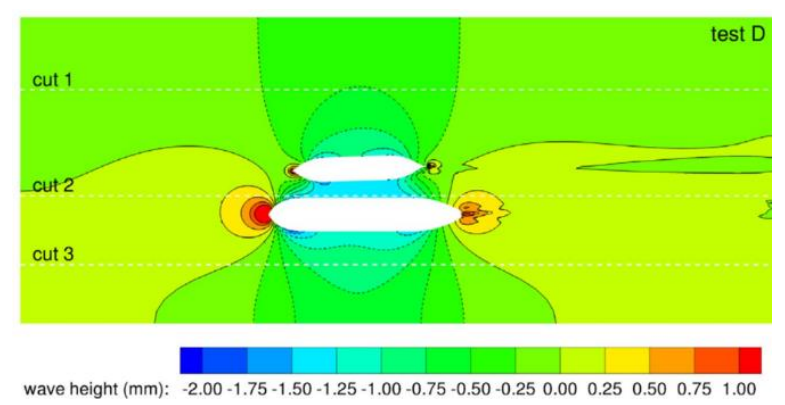

Figure 17. Wave patterns. (a) Present calculation; (b) CFD results from Zou and Larsson (2013b).

The wave pattern obtained from MHydro is shown in Figure 17 (a) and the CFD results (Zou and Larsson, 2013b) are shown in Figure 17 (b). The label 
'test D' in the right-top of Figure 17 (b) corresponds to test conditions of Test 1 in the present study. Generally, a very good agreement has been obtained between these two programs. Only very small discrepancies have been found in the stern areas of both ships, which is due to the influence from the propeller. In the present calculation, based on the potential flow theory, the influence from the propeller has been neglected. Figure 18 shows the wave profiles measured from three wave gauges. The present results from MHydro and the CFD results from SHIPFLOW (Zou and Larsson, 2013b) are also presented. The positive $x$ values represent the upstream part of the domain. It can be found from these figures that the present predictions agree with the measurements and CFD results very well at wave gauge 1 and 3 . At wave gauge 2 , the present method under-estimates the wave elevation between the two ships. But it matches the CFD method very well, which indicates that the viscous effects on the wave elevation are very small.
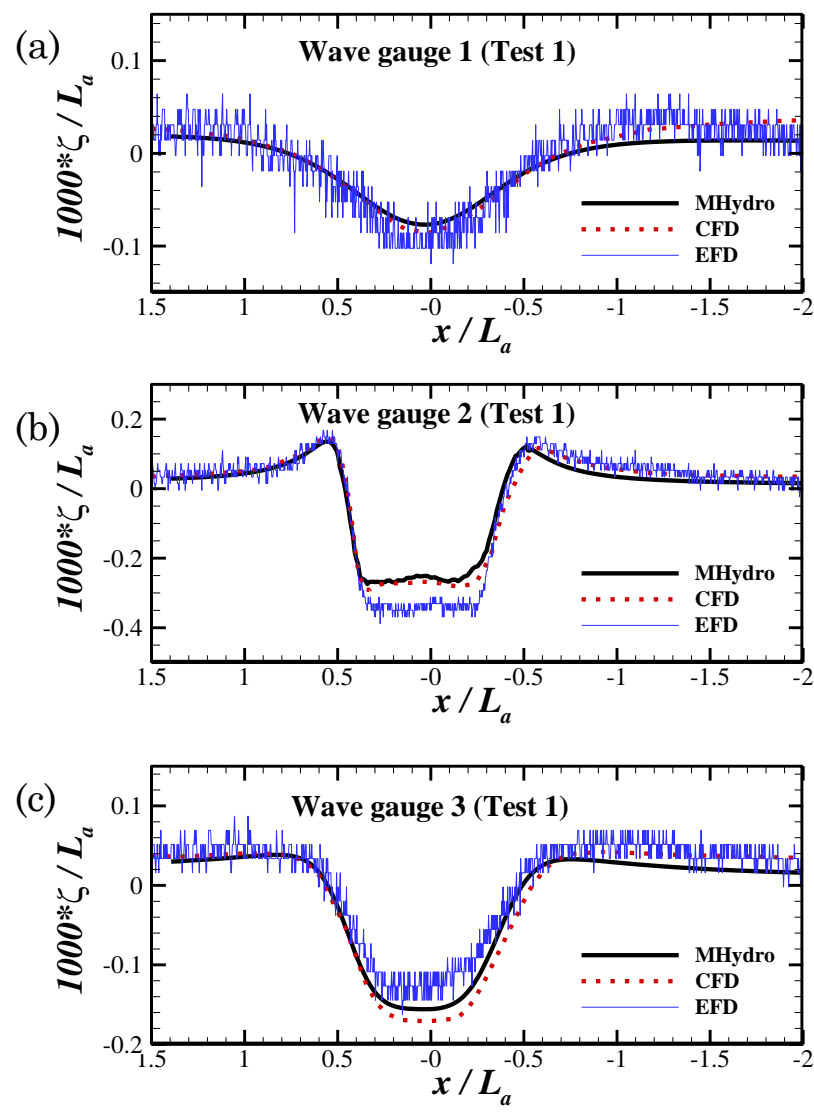

Figure 18. Wave profiles of Test 1. (a) Wave gauge 1; (b) wave gauge 2; (3) wave gauge 3 .

\section{2 (b) Validation of forces}

The model test data on the ship-to-ship encountering problem is very rare. To run the tests, an auxiliary carriage must be installed, in addition to the main carriage. In the present study, the benchmark data published by Vantorre, et al. (2002) is used to validate the present numerical results of the encountering cases. Two ship models with scale factor 1/75 are used for encountering tests (referred as Model D and Model E). The main particulars of Model D and Model $\mathrm{E}$ in model scale can be found in Table 4. In the model test, Model E was towed by the main carriage along the center line $(y=0)$ of the tank at $U_{E}=0.238 \mathrm{~m} / \mathrm{s}$, 
while Model $\mathrm{D}$ was towed by an auxiliary carriage at $U_{D}=-2 U_{E}$. The transverse distance is $d t=B_{D}+0.5 B_{E}$ and the water depth $d$ is $0.248 \mathrm{~m}$.

Table 4. Main particulars of Model D and Model E.

\begin{tabular}{lll}
\hline & Model E & Model D \\
\hline Length $(m)$ & $L_{E}=3.824$ & $L_{D}=3.864$ \\
Breadth $(m)$ & $B_{E}=0.624$ & $B_{D}=0.55$ \\
Draft $(m)$ & $T_{E}=0.207$ & $T_{D}=0.18$ \\
Block coefficient & $C_{B E}=0.816$ & $C_{B D}=0.588$ \\
\hline
\end{tabular}

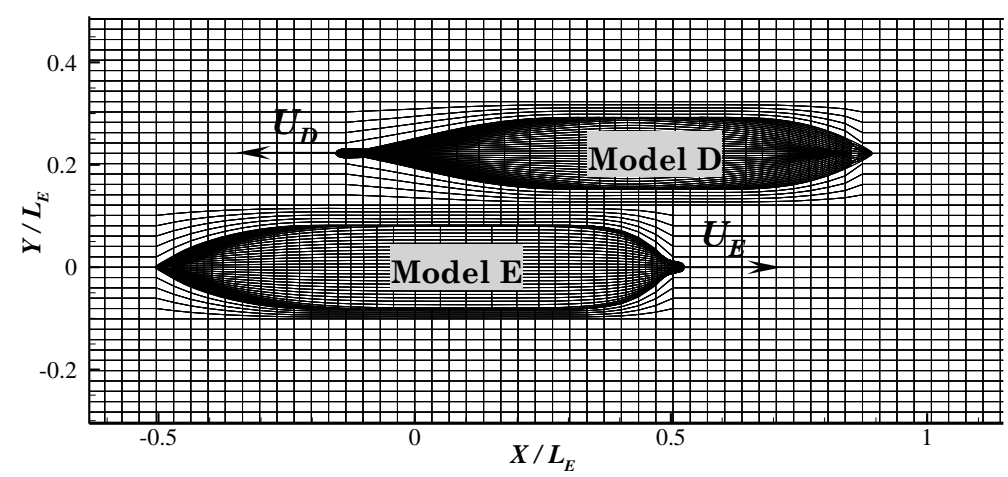

Figure 19. Panel distribution on partial computational domain. There are 9,950 panels distributed on the entire computational domain: 1,900 on the wetted body surface of Model E, 2,170 on the wetted body surface of Model D, 5,880 on the free-surface. The free-surface is truncated at $2 L_{E}$ upstream and $2 L_{E}$ downstream with regard to the bodyfixed frame on Model E.

Figure 19 shows the partial computational domain and mesh distribution. It should be noted that the side walls of the tank are not modelled. In order to minimize the panel number, the free-surface is truncated at $0.27 L_{E}$ and $0.42 L_{E}$ on either side with regard to Model D and Model E respectively. In calm water test, it has been proved by Yuan and Incecik (2016) that the side wall effects are negligible at $d_{s b} / L>0.25$ and $F_{r}<0.25$. It should also be noted that in the encountering simulations, the longitudinal distance $d_{l}$ is measured in the bodyfixed frame on Model E. The longitudinal distance between two ships at the moment shown in Figure 19 has a positive sign. The time step $\Delta t$ in the numerical calculation is $0.18 s$. The results are shown in Figure 20. Generally, the agreement between the present potential flow solver, MHydro, and the experimental measurements is very good, which indicates the potential flow method is applicable for predicting the hydrodynamic interactions between two ships travelling with different speeds. The numerical results obtained by using a rigid free-surface condition is also shown in Figure 20. As the encountering speed of the two models is very slow $\left(F_{r}=0.04\right.$ and $F_{r}=0.08$ for Model E and Model D respectively), the effect of free-surface waves is not essential. The results obtained by using MHydro are very close to the results obtained by using a rigid wall free-surface condition. However, as the overtaking or encountering speed increases, the far-field waves will become manifest, and the free-surface condition must be taken into account accordingly.

The results shown in Figure 20 (a) indicate the hydrodynamic interaction force plays a dominant role in total resistance, and the frictional component due to 
the viscosity is negligible. Even though the viscous effect is not taken into account, the potential flow method still overestimates the total resistance. The negative values shown in Figure 20 (a) represent the resistance which is opposite to the moving direction, while the positive values represent a thrust which is the same as the moving direction. An interesting finding is that a very large thrust force can be observed at $d_{l} / L_{E}=-0.5$. Physically, it can be explained that before encountering $\left(0<d_{l} / L_{E}<1\right)$, the presence of the other moving vessel stops the water from spreading evenly into the surrounding field. As a result, the pressure distributed over the ship bow increases. At the same time, the pressure distributed over the ship stern retains the same level. An increased resistance can be expected by the pressure integral. After the encounter $(-1<$ $d_{l} / L_{E}<0$ ), a high-pressure area transfers to the ship stern, which will consequently lead to a propulsive force. During the encountering process, the symmetry of the flow in the starboard and port side is violated by the presence of the other vessel. The maximum asymmetric flow occurs when the two ships are configured side-by-side $\left(d_{l} / L_{E}=0\right.$, as shown in Figure 1 (c)), where the suction force reaches its peak value (see Figure 20 (b)). The pressure distribution is not only asymmetric on the port and starboard sides, but also on the bow and stern. As a result, a very large yaw moment is observed in Figure 20 (c). It should be noted that compared to the ship-bank and the ship-lock problems, the amplitude of the yaw moment in the ship-ship problem is much larger. In the ship-bank and the ship-lock problem, the potential flow method fails to predict the sign of the yaw moment due to the weak lifting force caused by the cross-flow in the stern. However, in the ship-ship problem, the hydrodynamic interaction is much more important than cross-flow effects. The predictions by the potential flow solver are therefore reliable.

(a)

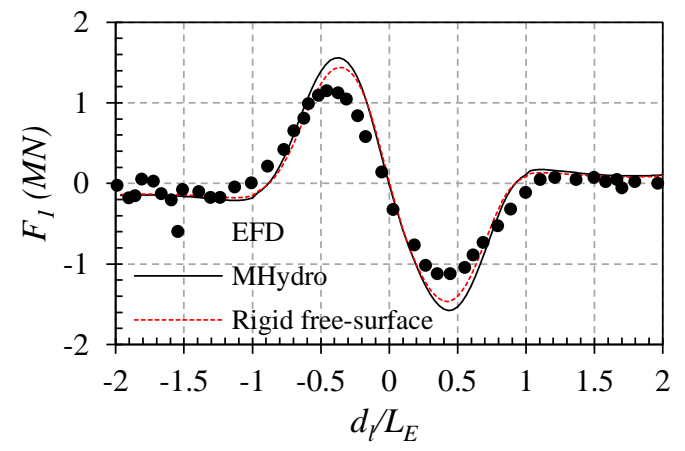

(b)

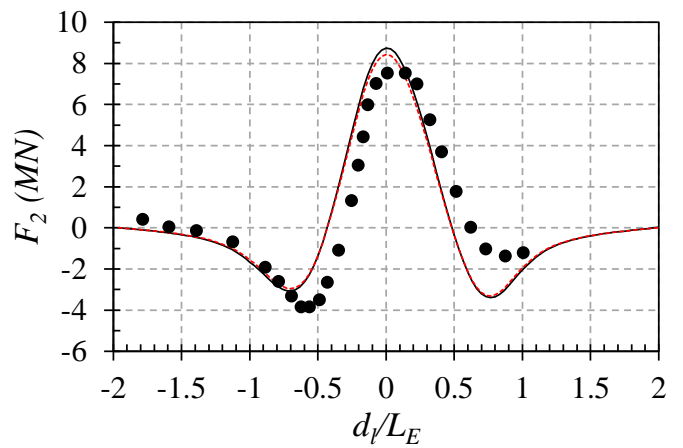


(c)

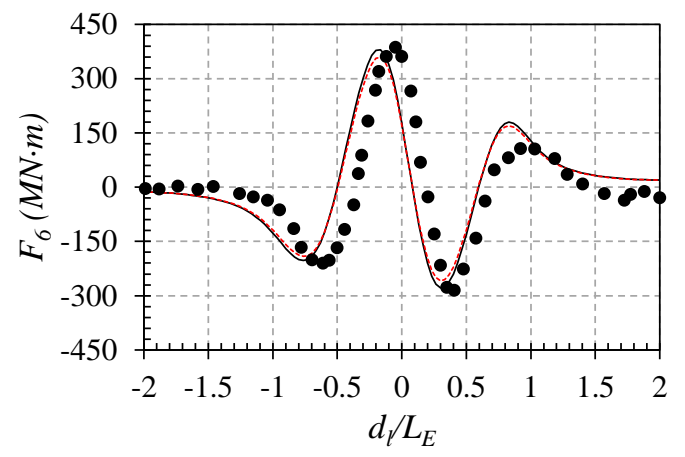

Figure 20. (a) The resistance, (b) the sway force and (c) the yaw moment acting on Model E encountered by Model D. The positive $d_{l}$ values denote that Model D is in the upstream side of Model E. As Model D moves to the downstream side, $d_{l}$ becomes negative. EFD results are published by Vantorre et al. (2002).

\section{CONCLUSIONS}

In the present study, an improved potential flow method was developed and its applicability in predicting ship hydrodynamics in confined waterways was discussed. Extensive validations were performed on the ship-bank, ship-bottom, ship-lock and ship-ship problems. Through the comparisons to the experimental measurements and CFD calculations, the following conclusions can be drawn:

1) The potential flow method provides a reliable way to predict the wave elevation when the bank and bottom effects are significant. Compared with the CFD programs, the present potential flow solver MHydro shows even better predictions of lateral forces and roll moments in ship-bank and ship-bottom problems. However, because the lifting forces are neglected due to the weak non-symmetrical flow, the potential flow method fails to predict the sign of the yaw moment. In order to estimate the yaw moment correctly, a so-called Kutta condition should be imposed on the trailing edge of the wake region.

2) The unsteady free-surface effects are very important in the ship-lock problem, while the viscous effect is less important. Neglecting the unsteady free-surface effects, the return flow and complex wave phenomenon cannot be captured. An empirical formula is introduced in the present study to estimate the return flow velocity. By complementing this return flow velocity with the boundary value problem, the modified potential flow solver could predict the resistance and lateral forces very well. However, it fails to predict the yaw moment due to the flow separation at the lock entrance and ship stern.

3) The potential flow method is very reliable for predicting the ship-ship problem. The hydrodynamic interaction plays a dominant role in total resistance. Even though the viscous effect is not taken into account, the potential flow method can still estimate the total resistance well. The yaw moment is also well predicted by the potential flow solver which indicates the cross-flow effects are less important compared with hydrodynamic interaction.

\section{ACKNOWLEDGEMENT}

The author thanks Mr. Jonathan Brown for language editing and proofreading this work. 


\section{REFERENCES}

Beck, R.F., Newman, J.N., Tuck, E.O., 1975. Hydrodynamic forces on ships in dredged channels. Journal of Ship Research 19 (3), 166-171.

Bunnik, T., 1999. Seakeeping calculations for ships, taking into account the non-linear steady waves, PhD thesis. Delft University of Technology, The Netherlands.

Dand, I.W., 1981. Some Measurements of Interaction Induced by Surface - Piercing and Flooded Banks, Feltham.

Eda, H., 1971. Directional Stability and Control, In Annual meeting of the Society of Naval Architects and Marine Engineers, New York, USA, pp. 72-116.

Fujino, M., 1968. Experimental Studies on Ship Manoeuvrability in Restricted Waters Part I. International Shipbuilding Progress 15 (168), 279-301.

Gourlay, T., 2008. Slender-body methods for predicting ship squat. Ocean Engineering 35 (2), 191 200.

Gourlay, T., 2009. Sinkage and trim of two ships passing each other on parallel courses. Ocean Engineering 36, 1119-1127.

Hoydonck, W.V., Toxopeus, S., Eloot, K., Bhawsinka, K., Queutey, P., Visonneau, M., 2015. Bank Effects for KVLCC2, World Maritime Technology Conference, Rhode Island, USA.

Kim, Y., Yue, D.K.P., Connell, B.S.H., 2005. Numerical dispersion and damping on steady waves with forward speed. Applied Ocean Research 27 (2), 107-125.

Lataire, E., Delefortrie, G., Vantorre, M., 2016. Impact of banks on ship squat, 4th MASHCON, Hamburg, Germany.

Lataire, E., Vantorre, M., Delefortrie, G., 2009. Captive model testing for ship to ship operations, MARSIM 2009, Panama City, Panama.

Lataire, E., Vantorre, M., Delefortrie, G., 2012a. A prediction method for squat in restricted and unrestricted rectangular fairways. Ocean Engineering 55, 71-80.

Lataire, E., Vantorre, M., Delefortrie, G., Candries, M., 2012b. Mathematical modelling of forces acting on ships during lightering operations. Ocean Engineering 55, 101-115.

Norrbin, N.H., 1975. Manoeuvring in confined waters: interaction phenomena due to side banks or other ships, Proceedings of the 14th ITTC, Ottawa, Canada.

Pinkster, J.A., Pinkster, H.J.M., 2014. A fast, user-friendly, 3-d potential flow program for the prediction of passing vessel forces, PIANC, San Francisco, USA.

Sakamoto, N., Wilson, R.V., Stern, F., 2007. Reynolds-Averaged Navier-Stokes Simulations for High-Speed Wigley Hull in Deep and Shallow Water Journal of Ship Research 51 (3), 187-203.

Schoenherr, K.E., 1960. Data for estimating bank suction effects in restricted water and on merchant ship hulls, 1st Symposium on ship maneuverability, SNAME, pp. 199-210.

Schultz, M.P., 2007. Effects of coating roughness and biofouling on ship resistance and powering. Biofouling 23 (5-6), 331-341.

Tezdogan, T., Incecik, A., Turan, O., 2015. A numerical investigation of the squat and resistance of ships advancing through a canal using CFD. Journal of Marine Science and Technology 21 (1), 86101.

Toxopeus, S., Bhawsinka, K., 2016. Calculation of Hydrodynamic Interaction Forces on A Ship

Entering A Lock Using CFD 4th MASHCON, Hamburg, Germany.

Tuck, E.O., 1964. A systematic asymptotic expansion procedure for slender ships. Journal of Ship Research 8, 15-23.

Tuck, E.O., 1966. Shallow water flows past slender bodies. Journal of Fluid Mechanics 26, 81-95.

Tuck, E.O., 1967. Sinkage and trim in shallow water of finite width. Schiffstechnik 14, 92-94. 
Tuck, E.O., Newman, J.N., 1974. Hydrodynamic interactions between ships, Proceedings of 10th Symposium on Naval Hydrodynamics, Cambridge, MA, USA, pp. 35-70.

Vantorre, M., 1995. Experimental Study of Bank Effects on Full form Ship Models, Proceedings of Mini Symposium on Ship Manoeuvrability, Fukuoka, Japan, pp. 85-101.

Vantorre, M., 2003. Experimental Investigation of Ship-Bank Interaction Forces, MARSIM 2003, Kanazawa, Japan.

Vantorre, M., Candries, M., Delefortrie, G., Eloot, K., Verwillingen, J., Henn, R., Vergote, T., et al. , 2016. A comparison of experimental and numerical behaviour characteristics of a ship entering a lock using benchmark test data. International Journal of Maritime Engineering 158 (A2), A-79-A-90.

Vantorre, M., Delefortrie, G., Mostaert, F., 2012. Behaviour of ships approaching and leaving locks: Open model test data for validation purposes. Version 3_0. WL Rapporten, WL2012R815_08e. Flanders Hydraulics Research and Ghent University - Division of Maritime Technology: Antwerp, Belgium.

Vantorre, M., Verzhbitskaya, E., Laforce, E., 2002. Model test based formulations of ship-ship interaction forces. Ship Technology Research 49, 124-141.

Vaz, G., Jaouen, F.A.P., Hoekstra, M., 2009. Free Surface Viscous Flow Computations. Validation of URANS Code FRESCO, 28 th International Conference on Ocean, Offshore and Arctic Engineering, Honolulu, Hawaii.

Wang, H.-Z., Zou, Z.-J., 2014. Numerical study on hydrodynamic interaction between a berthed ship and a ship passing through a lock. Ocean Engineering 88 (0), 409-425.

Xu, H., Zou, Z., Zou, L., Liu, X., 2016. Unsteady hydrodynamic interaction between two cylindroids in shallow water based on high-order panel method. Engineering Analysis with Boundary Elements 70, 134-146.

Yao, J.-X., Zou, Z.-j., 2010. Calculation of ship squat in restricted waterways by using a 3D panel method. Journal of Hydrodynamics, Ser. B 22 (5), 489-494.

Yeung, R.W., 1978. On the interactions of slender ships in shallow water. Journal of Fluid Mechanics 85, 143-159.

Yeung, R.W., Tan, W.T., 1980. Hydrodynamic interactions of ships with fixed obstacles. Journal of Ship Research 24 (1), 50-59.

Yuan, Z.-M., Incecik, A., Day, A.H., 2014. Verification of a new radiation condition for two ships advancing in waves. Applied Ocean Research 48, 186-201.

Yuan, Z.-M., Ji, C.-Y., Incecik, A., Zhao, W., Day, A., 2016. Theoretical and numerical estimation of ship-to-ship hydrodynamic interaction effects. Ocean Engineering 121, 239-253.

Yuan, Z.M., He, S., Paula, K., Incecik, A., Turan, O., Boulougouris, E., 2015. Ship-to-Ship Interaction during Overtaking Operation in Shallow Water. Journal of Ship Research 59 (3), 172-187.

Yuan, Z.M., Incecik, A., 2016. Investigation of side wall and ship model interaction, ICMT2016, Harbin, China.

Zhou, X., Sutulo, S., Guedes Soares, C., 2012. Computation of ship hydrodynamic interaction forces in restricted waters using potential theory. Journal of Marine Science and Application 11 (3), 265 275.

Zou, L., Larsson, L., 2013a. Computational fluid dynamics (CFD) prediction of bank effects including verification and validation. Journal of Marine Science and Technology 18 (3), 310-323.

Zou, L., Larsson, L., 2013b. Numerical predictions of ship-to-ship interaction in shallow water. Ocean Engineering 72, 386-402.

\section{AUTHORS BIOGRAPHY}

Dr. Zhi-Ming Yuan holds the current position as a lecturer in hydrodynamics at University of Strathclyde. His research interests mainly lie in the theoretical 
and numerical analysis of hydrodynamic performance of the ships and offshore structures. 